\title{
The RASSF6 Tumor Suppressor Protein Regulates Apoptosis and Cell Cycle Progression via Retinoblastoma Protein
}

\author{
aDepartment of Medical Biochemistry, Graduate School of Medical and Dental Sciences, Tokyo Medical and \\ Dental University, Tokyo, Japan \\ bDepartment of Biochemistry and Molecular Biology, University of Rajshahi, Rajshahi, Bangladesh \\ cCenter for Brain Integration Research, Tokyo Medical and Dental University, Tokyo, Japan
}

Shakhawoat Hossain, ${ }^{\mathrm{a}, \mathrm{b}}$ Hiroaki Iwasa, ${ }^{a}$ Aradhan Sarkar, ${ }^{a}$ Junichi Maruyama, ${ }^{a}$ Kyoko Arimoto-Matsuzaki, ${ }^{a}$ Yutaka Hata,

\begin{abstract}
RASSF6 is a member of the tumor suppressor Ras association domain family (RASSF) proteins. RASSF6 is frequently suppressed in human cancers, and its low expression level is associated with poor prognosis. RASSF6 regulates cell cycle arrest and apoptosis and plays a tumor suppressor role. Mechanistically, RASSF6 blocks MDM2-mediated p53 degradation and enhances p53 expression. However, RASSF6 also induces cell cycle arrest and apoptosis in a p53-negative background, which implies that the tumor suppressor function of RASSF6 does not depend solely on p53. In this study, we revealed that RASSF6 mediates cell cycle arrest and apoptosis via $\mathrm{pRb}$. RASSF6 enhances the interaction between $\mathrm{pRb}$ and protein phosphatase. RASSF6 also enhances P16INK4A and P14ARF expression by suppressing BMI1. In this way, RASSF6 increases unphosphorylated $\mathrm{pRb}$ and augments the interaction between $\mathrm{pRb}$ and E2F1. Moreover, RASSF6 induces TP73 target genes via pRb and E2F1 in a p53-negative background. Finally, we confirmed that RASSF6 depletion induces polyploid cells in p53-negative HCT116 cells. In conclusion, RASSF6 behaves as a tumor suppressor in cancers with loss of function of $\mathrm{p53}$, and $\mathrm{pRb}$ is implicated in this function of RASSF6.
\end{abstract}

KEYWORDS RASSF6, RB1, apoptosis, cell cycle arrest, tumor suppressor

D. as association domain family 6 (RASSF6) is a member of the RASSF proteins (1-3). RASSF6 is epigenetically silenced in acute lymphocytic leukemia, chronic lymphocytic leukemia, neuroblastoma, metastatic melanoma, and gastric cardia adenocarcinoma (4-8). RASSF6 suppression is more frequently observed in gastric cancer, pancreatic ductal adenocarcinoma, and gastric cardia adenocarcinoma the advanced stage (8-10). These findings support the tumor-suppressive role of RASSF6.

Exogenously expressed RASSF6 induces apoptosis in caspase-dependent and caspase-independent manners in various cells (11). Conversely, RASSF6 depletion blocks tumor necrosis factor $\alpha$-induced apoptosis in HeLa cells, okadaic acid-induced apoptosis in rat hepatocytes, and sorbitol-induced apoptosis in human renal proximal tubular epithelial cells (11-13). RASSF6 also causes $G_{1} / S$ arrest and is implicated in UV-induced cell cycle arrest (14).

The Hippo pathway is a tumor-suppressive signaling pathway that comprises mammalian Ste20-like 1 and 2 (MST1/MST2) kinases and large tumor suppressor 1 and 2 (LATS1/LATS2) kinases (15-17). RASSF6 interacts with the MST1/MST2 kinases and inhibits kinase activity (12). Reciprocally MST1/MST2 suppress RASSF6-induced apoptosis. When cells are exposed to okadaic acid, which activates the Hippo pathway, RASSF6 and MST1/MST2 are dissociated. Consequently, RASSF6 induces apoptosis. In this manner, RASSF6 cooperates with the Hippo pathway to function as a tumor suppressor.
Received 26 January 2018 Returned for modification 1 March 2018 Accepted 7 June 2018

Accepted manuscript posted online 11 June 2018

Citation Hossain S, Iwasa H, Sarkar A, Maruyama J, Arimoto-Matsuzaki K, Hata Y. 2018. The RASSF6 tumor suppressor protein regulates apoptosis and cell cycle progression via retinoblastoma protein. Mol Cell Biol 38:e0046-18. https://doi .org/10.1128/MCB.00046-18.

Copyright $\odot 2018$ American Society for Microbiology. All Rights Reserved. Address correspondence to Yutaka Hata, yuhammch@tmd.ac.jp. 
RASSF6 binds to MDM2 and blocks p53 degradation by MDM2 (14). UV enhances p53 expression and triggers the transcription of p53 target genes that are implicated in apoptosis and cell cycle regulation. RASSF6 depletion attenuates UV-triggered increase of p53 expression and blocks the induction of p53 target genes. MDM2-p53 is instrumental in the tumor-suppressive role of RASSF6. Nevertheless, RASSF6 induces apoptosis even in p53-compromised HeLa cells and p53-negative HCT116 (HCT116 p53-/-) cells, suggesting that RASSF6 controls apoptosis via a specific molecule other than $\mathrm{p} 53$. Modulator of apoptosis 1 (MOAP1), the activator of Bax, binds to RASSF6 $(12,18,19)$. MOAP1 depletion attenuates RASSF6-induced apoptosis. The double knockdown of MOAP1 and p53, however, does not exhibit additional effects on RASSF6-induced apoptosis (14). This means that MOAP1 is located in the same pathway as p53.

Retinoblastoma protein (pRb) and p53 are thought to be the two major tumor suppressors (20-23). RB1, which encodes $\mathrm{pRb}$, is mutated in familial retinoblastoma. Unphosphorylated pRb forms a complex with E2F1 and inhibits E2F1-mediated transcription $(24,25)$. The phosphorylation of $\mathrm{pRb}$ by cyclin-dependent kinases (CDKs) releases E2F1 from $\mathrm{pRb}$ and promotes the cell cycle. In this study, we examined the implication of $\mathrm{pRb}$ in the tumor-suppressive role of RASSF6. We demonstrate that RASSF6 reduces the phosphorylation of $\mathrm{pRb}$ to enhance the interaction of $\mathrm{pRb}$ and E2F1. Furthermore, in the presence of RASSF6, E2F1 mediates transcription of proapoptotic TP73 and CASP7 in HCT116 p53-/- cells. Consistent with this, the suppression of $R B 1$ and E2F1 decreases RASSF6-mediated apoptosis.

\section{RESULTS}

Depletion of RB1 overrides RASSF6-induced cell cycle arrest. We tested the effect of RASSF6 on the cell cycle in a p53-negative background. Exogenously expressed RASSF6 blocked EdU incorporation in HCT116-p53-1- cells (Fig. 1A, siCont., arrowheads). However, when RB1 was knocked down (Fig. 1C), EdU was incorporated in RASSF6-expressing cells (Fig. 1A, siRB1\#1 and siRB1\#2, arrows). In the quantification, almost $80 \%$ of control cells incorporated EdU, whether RB1 was knocked down or not (Fig. 1B, black bars). RASSF6 reduced the incorporation of EdU to $10 \%$ (Fig. 1B, siCont., gray bar), but $R B 1$ silencing recovered it to about $40 \%$ (Fig. 1B, siRB1\#1 and siRB1\#2, gray bars).

RASSF6 blocks the phosphorylation of $\mathrm{pRb}$ and enhances the interaction between $\mathbf{p R b}$ and E2F1. The interaction between $\mathrm{pRb}$ and E2F1 is regulated by the phosphorylation of pRb by CDKs $(20,26,27)$. Phosphorylation at threonine 821 induces the intramolecular binding of the C-terminal domain to the pocket domain and blocks the interaction between pRb and E2F1 $(24,27)$. Phosphorylation at serine 608 also inhibits the interaction between pRb and E2F1 (28). RASSF6 remarkably reduced the phosphorylation at serine 608 and slightly attenuated the phosphorylation at threonine 821 (Fig. 2A). Conversely RASSF6 silencing augmented the phosphorylation at these sites (Fig. 2B). Serine $807 / 811$ are phosphorylated by CDK4 and are reported to be required for phosphorylation at other sites $(24,29-31)$. Serine 807 phosphorylation is also considered to play a role in $G_{0} / G_{1}$ transition and binding to Bax $(32,33)$. RASSF6 decreased phosphorylation at serine 807/811, while RASSF6 silencing augmented it (Fig. $2 \mathrm{~A}$ and $\mathrm{B})$. To further confirm the effect of RASSF6, we examined the phosphorylation states of $\mathrm{pRb}$ in the cytoplasmic and nuclear fractions. Cytoplasmic pRb was not detected by the antibody specific for unphosphorylated $\mathrm{pRb}$, which does not recognize phosphorylated pRb (Fig. 2C, third gel from top). To more clearly separate phosphorylated and unphosphorylated pRb, we used Phos-tag gels, in which phosphorylated proteins migrate slowly. The analysis with Phos-tag gels revealed that the major part of the cytoplasmic pRb was phosphorylated while most of the nuclear $\mathrm{pRb}$ was unphosphorylated, but phosphorylated pRb was also detected in the nucleus (Fig. 2C, top, arrow). However, the coexpression of RASSF6 reduced the nuclear phosphorylated $\mathrm{pRb}$ (Fig. 2C, top, arrowhead). All these findings indicate that RASSF6 reduces the phosphorylation of $\mathrm{pRb}$. In a coimmunoprecipitation experiment using HEK293FT cells, RASSF6 augmented the interaction between E2F1 and pRb, which is consistent with the 
A
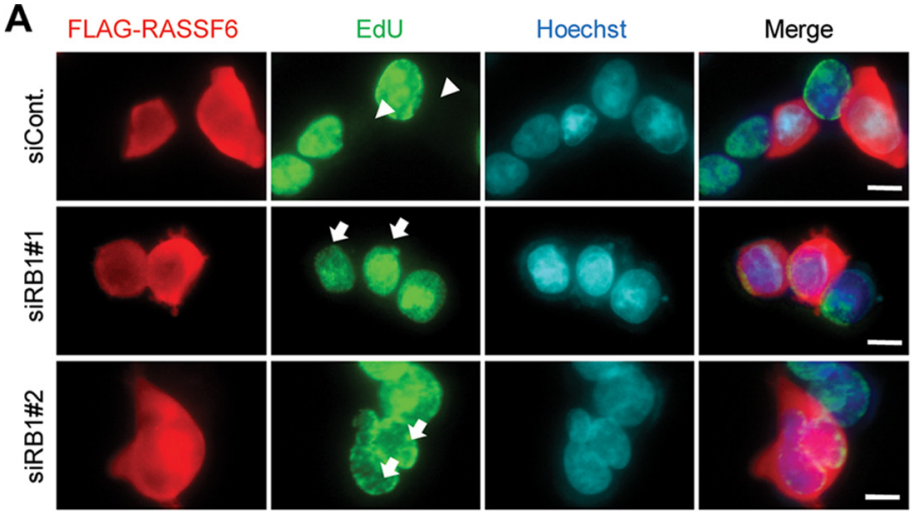

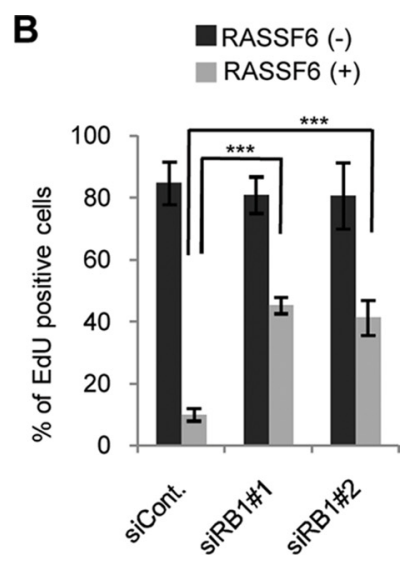

C
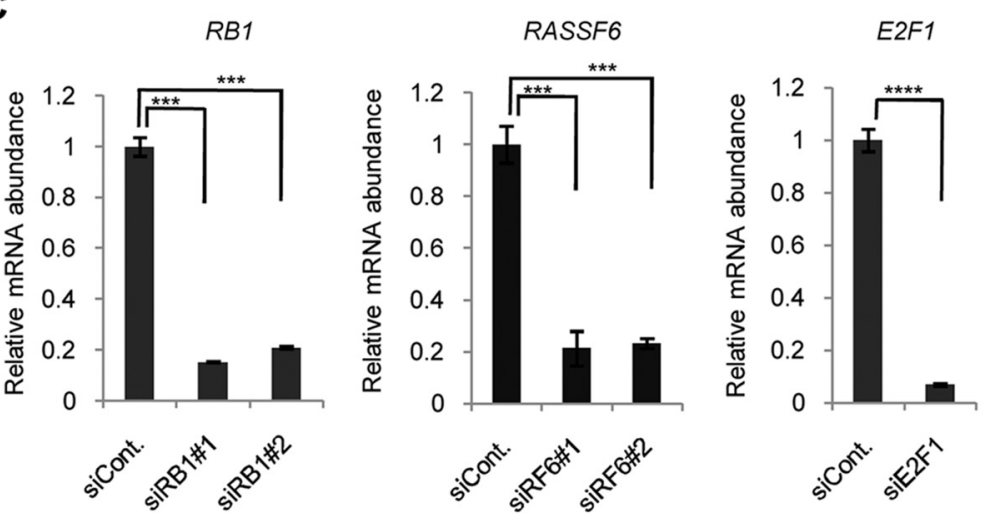

FIG 1 RASSF6 suppresses EdU incorporation via pRb. (A) HCT116 p53-/- cells were transfected with control siRNA or RB1 siRNAs; $48 \mathrm{~h}$ later, the cells were replated at $5 \times 10^{4}$ cells/well in a 12-well plate and transfected with pCIneoFHF-RASSF6 (FLAG-RASSF6). Six hours after transfection, the cells were treated with $2 \mathrm{mM}$ thymidine, cultured for $18 \mathrm{~h}$, and then released from the thymidine block. Two hours later, the cells were treated with $10 \mu \mathrm{M}$ EdU for $1 \mathrm{~h}$, fixed, and immunostained with anti-FLAG and anti-EdU antibodies. The nuclei were visualized with Hoechst 33342. (Top row) The arrowheads indicate that FLAG-RASSF6-expressing cells did not incorporate EdU. (Middle and bottom rows) The arrows indicate FLAG-RASSF6-expressing cells that incorporated EdU. Bars, $10 \mu \mathrm{m}$. (B) One hundred fifty FLAG-positive and -negative cells were observed. The ratio of the cells incorporating EdU was calculated. Three independent samples were evaluated. The data indicate means with standard deviations (SD). ***, $P<0.001$. (C) Validation of RB1, RASSF6, and E2F1 silencing in HCT116 p53 $3^{-1-}$ cells. HCT116 p53-/- cells were transfected with control, two RB1, two RASSF6, and E2F1 siRNAs; $96 \mathrm{~h}$ later, mRNAs were extracted and quantitative RT-PCR was performed. ${ }^{* *}, P<0.001 ;{ }^{* * * *}, P<0.0001$.

decreased phosphorylation at serine 608 and threonine 821 (Fig. 2D, arrow). Furthermore, RASSF6 suppressed the E2F1 promoter reporter (Fig. 2E, siCont.), but RB1 silencing abrogated this inhibition, supporting the notion that RASSF6 inhibits E2F1 via pRb (Fig. 2E, siRB1\#1). Consistently, RASSF6 silencing enhanced the E2F1 promoter reporter (Fig, 2F). It has been reported that LATS2 is implicated in the assembly of DREAM, which represses E2F1 target gene transcription (34). Considering that RASSF6 cross talks with the Hippo pathway, we silenced LATS1 and LATS2. However, RASSF6 suppressed the E2F1 promoter reporter even in the LATS1-LATS2-negative background (Fig. 2G). Moreover, the depletion of LIN52, which is a component of the DREAM complex (29), did not affect RASSF6-mediated suppression of the E2F1 promoter reporter (Fig. 2H). These findings suggest that RASSF6 functions independently of the DREAM complex.

RASSF6 promotes the interaction between $\mathbf{p R b}$ and protein phosphatases. $\mathrm{pRb}$ phosphorylation is regulated by protein phosphatases (PP1A and PP2A) (35). In Drosophila melanogaster, dRASSF, a fly homologue of RASSF, interacts with fly homologues of components of the striatin-interacting protein phosphatases and kinases (STRIPAK) complexes (36). STRIPAK is a complex of PP2A that interacts with Ste20-like kinases (37). In mammals, although direct interaction between RASSF and the STRIPAK complex has 
A

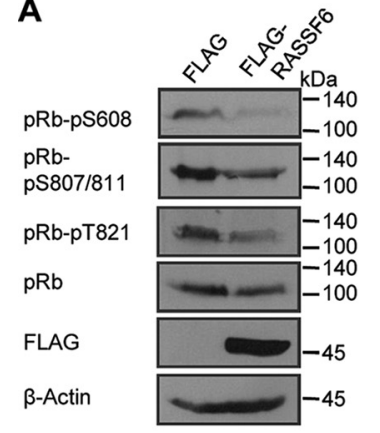

B

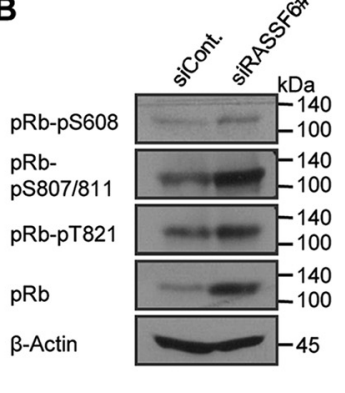

C

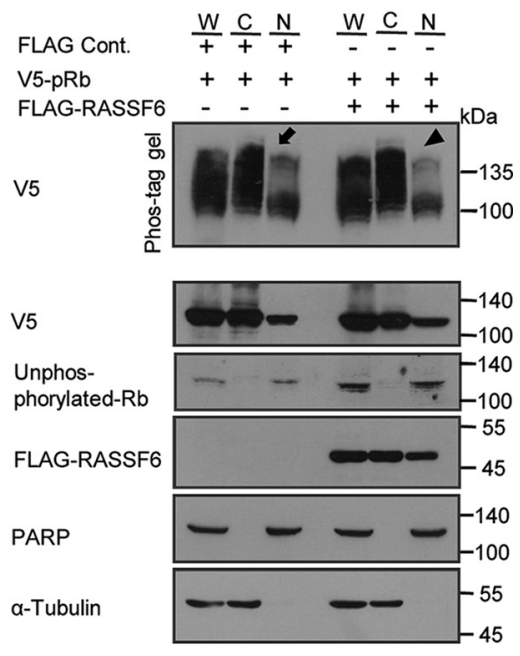

$\mathbf{F}$

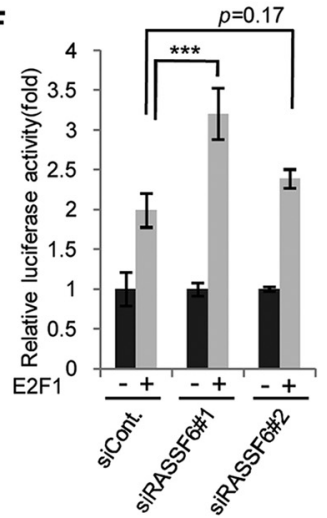

D

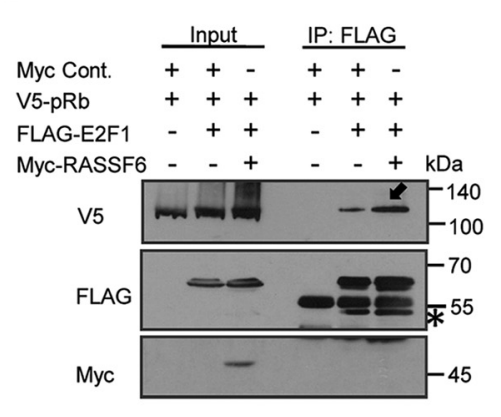

E

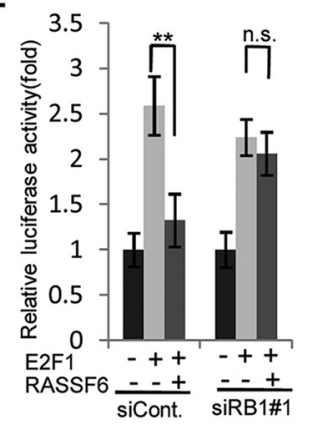

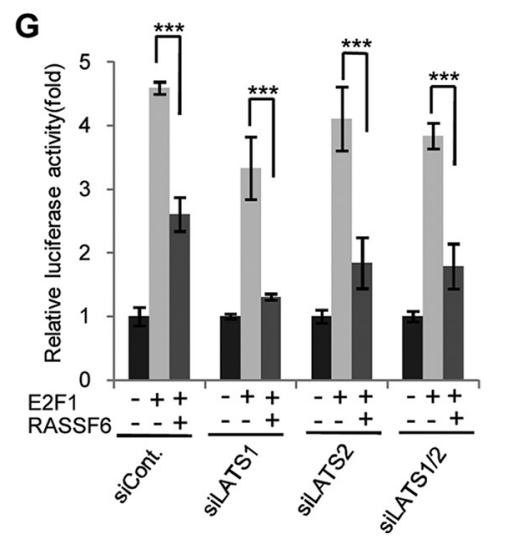
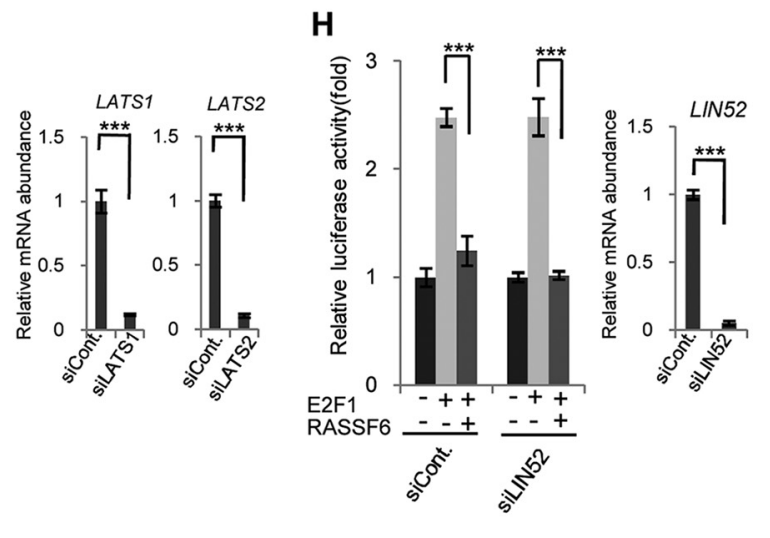

FIG 2 RASSF6 suppresses pRb phosphorylation and enhances interaction between pRb and E2F1. (A) The cell lysates of parental HCT116 p53-/- cells transfected with control pCIneoFHF (FLAG) or pCIneoFHF-RASSF6 (FLAGRASSF6) were immunoblotted with the indicated antibodies to detect endogenous pRb and to evaluate phosphorylation. (B) HCT116 p53-/- cells were transfected with control siRNA (siCont.) or RASSF6 siRNA (siRASSF6\#1); $72 \mathrm{~h}$ later, the cell lysates were immunoblotted with the indicated antibodies. (C) V5-pRb (pLX304-pRb-V5) was expressed alone or with FLAG-RASSF6 in HCT116 p53-/- cells; 24 h later, the cells were harvested, and subcellular fractionation was performed. Comparable amounts of whole-cell lysates (W), the cytoplasmic fraction (C), and the nuclear fraction $(\mathrm{N})$ were analyzed by SDS-PAGE for immunoblotting with anti-FLAG, anti-V5, anti-unphosphorylated-Rb, anti-poly(ADP-ribose) polymerase (PARP), and anti- $\alpha$-tubulin antibodies or on a Phos-tag gel for immunoblotting with anti-V5 antibody to evaluate phosphorylated and unphosphorylated pRb. PARP and $\alpha$-tubulin were used as nuclear and cytoplasmic markers. The arrow indicates the phosphorylated pRb in the nuclear fraction. As indicated by the arrowhead, RASSF6 reduced the phosphorylated pRb in the nuclear fraction. (D) HEK293FT cells were transfected with various combinations of pLX304-pRb-V5, pClneoFH-E2F1, and pCIneoMyc-RASSF6. Immunoprecipitation was performed with anti-DYKDDDDK (1E6) antibody beads. The inputs and immunoprecipitates were immunoblotted with the indicated antibodies. In the presence of RASSF6, the

(Continued on next page) 
not been reported, RASSF proteins have been detected in the interactome of MST kinases and the STRIPAK complex (38). We hypothesized that RASSF6, as a scaffold, promotes the interaction between $\mathrm{pRb}$ and protein phosphatases and facilitates dephosphorylation of $\mathrm{pRb}$. We immunoprecipitated RASSF6 from human colon cancer SW480 cells and detected pRb that was coimmunoprecipitated with RASSF6 (Fig. 3A, arrow). To further confirm the interaction, we exogenously expressed RASSF6 and pRb in HEK293FT cells and performed a coimmunoprecipitation experiment. When FLAGRASSF6 was immunoprecipitated, V5-pRb was coimmunoprecipitated (Fig. 3B, left). In the reverse experiment, FLAG-RASSF6 was coimmunoprecipitated with V5-pRb (Fig. 3B, right). In the experiment shown in Fig. $2 \mathrm{C}$, we noted that RASSF6, when coexpressed with $\mathrm{pRb}$, was recovered not only in the cytoplasm but also in the nucleus (Fig. $2 \mathrm{C}$, second gel from top). This observation prompted us to ask whether pRb affects the subcellular localization of RASSF6. We expressed FLAG-RASSF6 with or without V5-pRb in HeLa cells and evaluated the subcellular localization in the immunofluorescence and in the subcellular fractionation (Fig. $3 C$ and D). FLAG-RASSF6 was distributed mainly in the cytoplasm (Fig. 3C, top, and D). However, when coexpressed with V5-pRb, FLAGRASSF6 was detected in the nucleus (Fig. 3C, bottom). The subcellular fractionation also supported the notion that pRb increased nuclear RASSF6 (Fig. 3D, arrow). We next examined the effect of RASSF6 on the interaction between protein phosphatases and pRb. We expressed luciferase-fused PP1A and PP2A with V5-pRb in HEK293FT cells and immunoprecipitated V5-pRb. The luciferase activity in the immunoprecipitates was measured to evaluate the coimmunoprecipitation of PP1A and PP2A with pRb. RASSF6 increased luciferase-PP1A and -PP2A coimmunoprecipitated with pRb (Fig. 3D). These findings are consistent with the assumption that RASSF6 promotes the interaction of $\mathrm{pRb}$ with protein phosphatases, allowing $\mathrm{pRb}$ to remain unphosphorylated. RASSF5 promotes dephosphorylation of pRb (39). RASSF1A blocks dephosphorylation of mammalian Ste20-like kinases (MST1 and -2) (40). As RASSF1 A and RASSF5 can interact with RASSF6 (41), it is possible that RASSF6 regulates the phosphorylation state of $p R b$ and the interaction of $\mathrm{pRb}$ with E2F1 through RASSF1A and RASSF5. However, neither RASSF1 silencing nor RASSF5 silencing had an effect on the RASSF6-mediated suppression of the E2F1 promoter reporter, which means that RASSF6 regulates $\mathrm{pRb}$ independently of RASSF1A and RASSF5 (see Fig. S1 in the supplemental material). As pRb and MDM2 interact with each other (42), we examined whether and how pRb affects the interaction between RASSF6 and MDM2. However, pRb did not show any effect (see Fig. $\mathrm{S} 2$ in the supplemental material).

RASSF6 induces CDKN2A independently of p53. Another explanation of the reduced phosphorylation of $\mathrm{pRb}$ is the inhibition of CDKs. As RASSF6 enhances p53 expression, we reasoned that RASSF6 upregulates CDKN1A (cyclin-dependent kinase inhibitor 1A) mRNA via p53 and inhibits the CDK2/CDK4-mediated phosphorylation of $\mathrm{pRb}$ via CDKN1A. However, in this study, we wanted to know how RASSF6 functions as a tumor suppressor in a p53-negative background. We therefore examined whether RASSF6 regulates CDKN1A and CDKN2A in HCT116 p53-/- cells. Treatment with doxorubicin enhanced P16INK4A and P14ARF, both of which are included in the CDKN2A locus at the mRNA level (Fig. 4A, siCont.). RASSF6 depletion abolished the enhancement of P16INK4A and P14ARF (Fig. 4A, siRASSF6\#1). Doxorubicin, although to a lesser extent,

FIG 2 Legend (Continued)

amount of coimmunoprecipitated pRb was increased (arrow). The asterisk indicates the immunoglobulin heavy chain. (E) HEK293FT cells were transfected with control siRNA or RB1 siRNA\#1; $48 \mathrm{~h}$ later, the cells were transfected with E2F1-Luc (-242) reporter and pCMV alkaline phosphatase. E2F1 (pCIneoFH-E2F1) and/or RASSF6 (pCIneoMycRASSF6) was coexpressed, and $24 \mathrm{~h}$ later, a luciferase assay was conducted with Picagene as a substrate. RASSF6 suppressed E2F1-mediated enhancement of luciferase activity (siCont., second and third bars), but RB1 knockdown abolished the effect of RASSF6. ${ }^{* *}, P<0.01$; n.s., not significant. (F) HEK293FT cells were transfected with control siRNA or RASSF6 siRNA (\#1 or \#2), The reporter assay was performed as described for panel E. ${ }^{* * *}, P<0.001$. (G) HEK293FT cells were transfected with LATS1 and LATS2 siRNAs. The reporter assay was performed as described for panel E. The validation of LATS1-LATS2 silencing is shown on the right. ${ }^{* * *}, P<0.001$. (H) HEK293FT cells were transfected with LIN52 siRNA. The reporter assay was performed as described for panel E. The validation of LIN52 silencing is shown on the right. ${ }^{* *}, P<0.001$. 
A

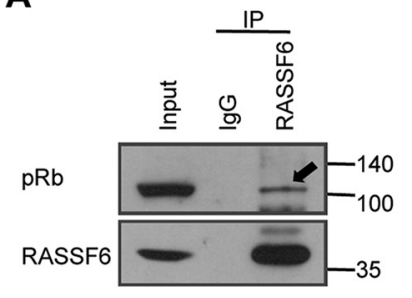

B

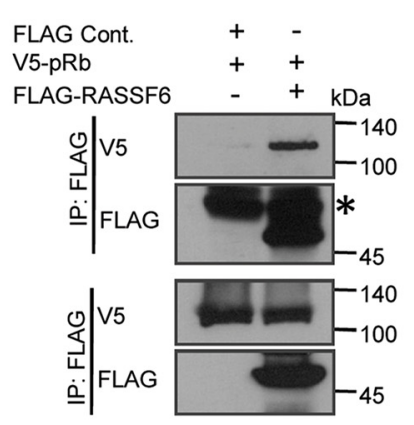

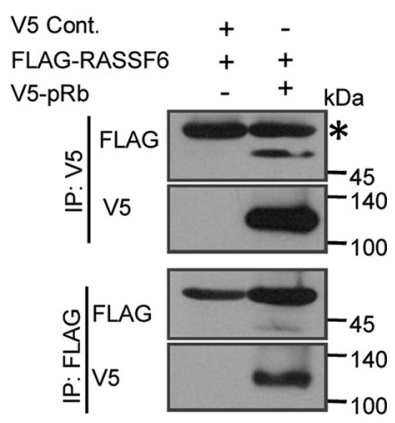

C
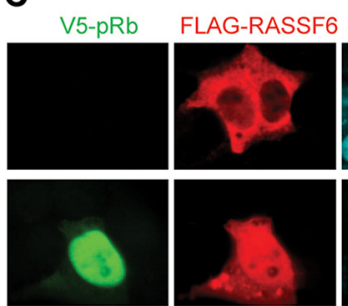

Hoechst

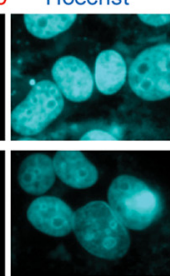

Merge

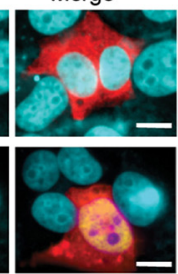

D

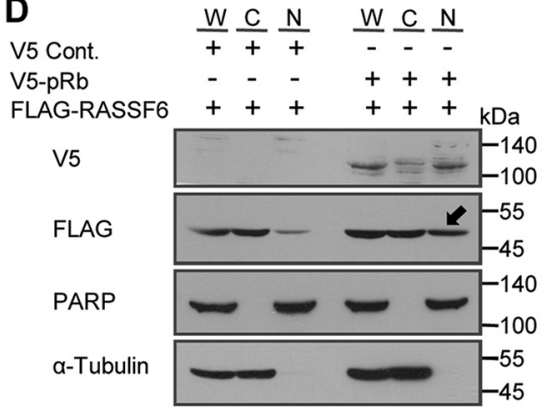

E

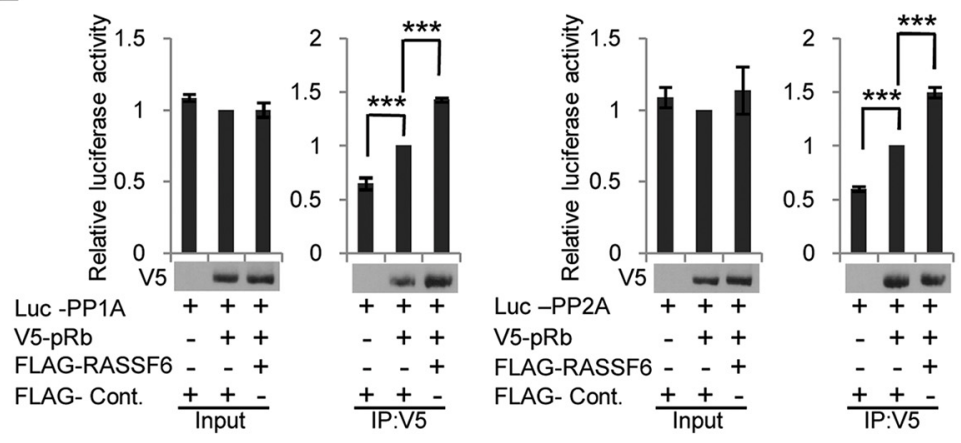

FIG 3 RASSF6 mediates the interaction between pRb and protein phosphatases. (A) RASSF6 was immunoprecipitated (IP) from SW480 cells. The inputs and the immunoprecipitates were immunoblotted with the indicated antibodies. The arrow indicates the coimmunoprecipitated pRb, (B) HEK293FT cells were transfected with pLX304pRb-V5 and either control pCIneoFHF (FLAG) or pCIneoFHF-RASSF6 (FLAG-RASSF6). Immunoprecipitation was performed with anti-DYKDDDDK (1E6) antibody (left) or anti-V5 antibody (right) beads. The inputs and immunoprecipitates were immunoblotted with the indicated antibodies. The asterisks indicate the immunoglobulin heavy chain. (C and D) FLAG-RASSF6 (pCIneoFHF-RASSF6) was expressed alone or with V5-pRb (pLX304-pRb-V5) in HeLa cells. (C) FLAG-RASSF6 was distributed in the cytoplasm when expressed alone but was detected in the nucleus when coexpressed with V5-pRb. Bars, $10 \mu \mathrm{m}$. (D) Subcellular fractionation was performed. Nuclear RASSF6 was increased when coexpressed with V5-pRb (arrow). (E) HEK293FT cells were transfected with various combinations of pCIneoLuc-PP1A, pCIneoLuc-PP2A, pLX304-pRb-V5, control pCIneoFHF, and pCIneoFHF-RASSF6. Immunoprecipitation was performed with anti-V5 antibody beads. The immunoprecipitated V5-pRb is shown below the graphs. Luciferase activities in the inputs and immunoprecipitates were measured by use of Picagene as a substrate. ${ }^{* * *}, P<0.001$. The error bars indicate SD.

enhanced CDKN1A in HCT116 p53 $3^{-1-}$ cells, but RASSF6 silencing had no effect on the enhancement of CDKN1A (Fig. 4A, CDKN1A). This implies that RASSF6 upregulates P16INK4A and P14ARF in the p53-negative background, inhibits CDK4 via the p16 protein, and eventually prevents the phosphorylation of $\mathrm{pRb}$. Moreover, it also suggests that CDKN1A is regulated independently of RASSF6 in a p53-negative background.

RASSF6 antagonizes BMI1. The next question was the mechanism by which RASSF6 enhances P16INK4A and P14ARF. As the Polycomb complex protein BMI1 is well known to downregulate P16INK4A and P14ARF expression, we suspected that BMI1 was implicated (43). We examined whether BMI1 silencing antagonized RASSF6 silencing. As 


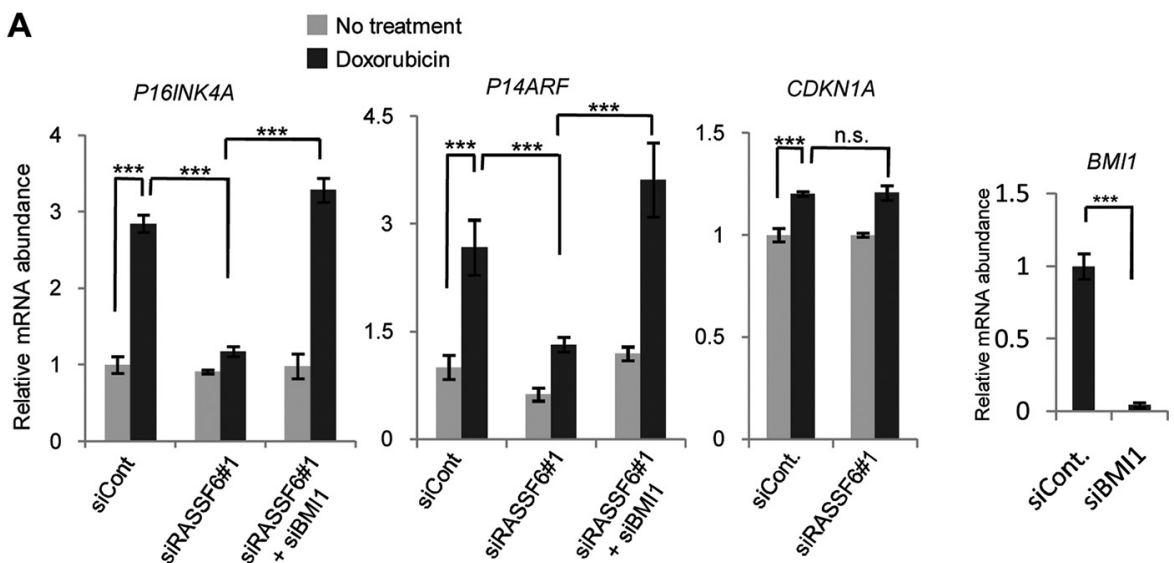

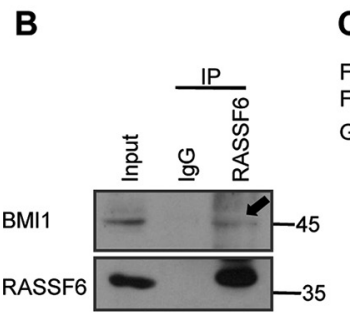

C

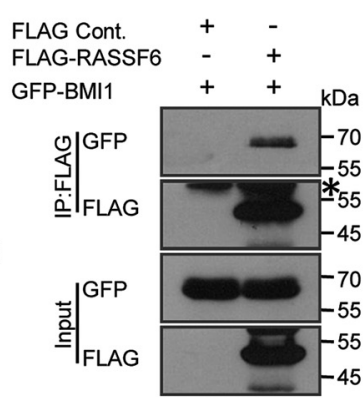

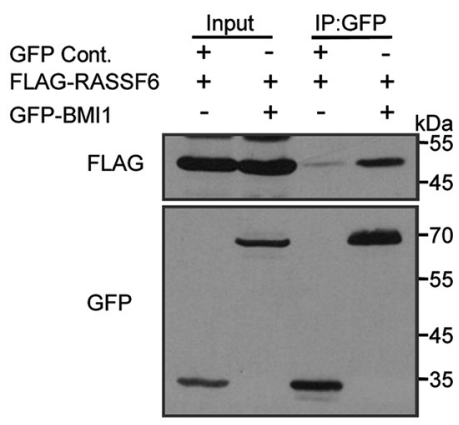

D

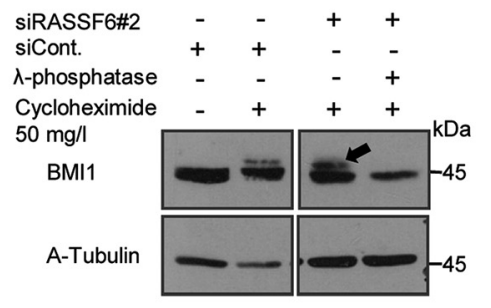

$\mathbf{F}$

siCont.

siRASSF6\#

Myc- $\beta$ TrCP

Cycloheximide

$50 \mathrm{mg} / \mathrm{l}$

BMI1

Myc

a-Tubulin

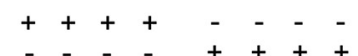

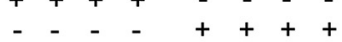

$++++++++$

$\begin{array}{llllllll}0 & 3 & 6 & 12 & 0 & 3 & 6 & 12(\mathrm{~h})\end{array}$

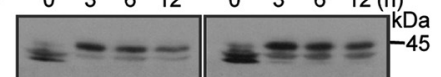

$=--\infty \quad z=-45$

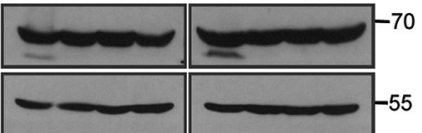

E

GFP-RASSF6 $\quad-\quad-\quad-\quad-\quad+\quad+\quad+$

$\begin{array}{lllllllll}\text { Cycloheximide } & 0 & 3 & 6 & 12 & 0 & 3 & 6 & 12(\mathrm{~h})\end{array}$

$50 \mathrm{mg} / \mathrm{l}$

BMl1

GFP

a-Tubulin

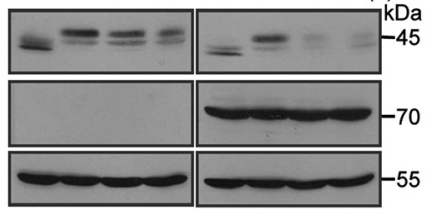

G

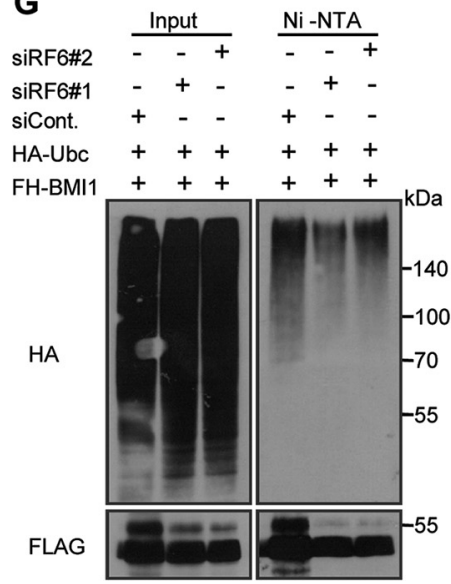

FIG 4 RASSF6 antagonizes BMI1 and is implicated in P16INK4A and P14ARF expression in a p53-negative background. (A) HCT116 p53 $3^{-1-}$ cells were transfected with the indicated siRNAs; $24 \mathrm{~h}$ later, the cells were exposed to $1 \mathrm{mg} /$ liter doxorubicin for $1 \mathrm{~h}$ and then washed. The cells were further cultured and harvested to isolate mRNAs. CDKN2A and P14ARF were examined after 5-day culture, while CDKN1A was evaluated after 2-day culture, with quantitative RT-PCR. RPS18 was used as a reference. Doxorubicin enhanced P16INK4A and P14ARF expression. Doxorubicin also enhanced CDKN1A expression, but to a lesser extent. RASSF6 knockdown abolished the effect of doxorubicin. However, additional BMI1 silencing recovered doxorubicin-induced enhancement of P16INK4A and P14ARF. ${ }^{* *}, P<0.001$; n.S., not significant. The

(Continued on next page) 
expected, the additional knockdown of BMI1 recovered the enhancement of P16INK4A and P14ARF in RASSF6-depleted cells (Fig. 4A, siRASSF6\#1+siBMI1). This observation supports the notion that RASSF6 antagonizes BMI1 in the regulation of P16INK4A and P14ARF. RASSF6 expression did not affect BMI1 mRNA expression (data not shown). We next tested whether and how RASSF6 affects BMI1 at the protein level. First, we tested the interaction between RASSF6 and BMI1. BMI1 was coimmunoprecipitated with RASSF6 from SW480 cells (Fig. 4B, arrow). We could also detect the interaction between exogenously expressed RASSF6 and BMI1 (Fig. 4C, right and left). We next examined the effect of RASSF6 on the stability of BMI1. We first confirmed that cycloheximide treatment induced a mobility shift of BMI1, as previously reported (Fig. 4D, left) (44). RASSF6 silencing increased the upward-shifted band (Fig. 4D, arrow). Treatment with $\lambda$-phosphatase abolished this shift (Fig. 4D, far-right lane). These findings support the notion that cycloheximide induces the phosphorylation of BMI1 and that RASSF6 silencing increases it. We next evaluated BMI1 degradation in the presence of RASSF6 (Fig. 4E). Green fluorescent protein (GFP)-RASSF6 slightly reduced BMI1 protein expression (Fig. 4E, 0 h). More remarkably, RASSF6 decreased the upward-shifted BMI1 (Fig. 4E, $3 \mathrm{~h}$ to $12 \mathrm{~h}$ ). $\beta \operatorname{TrCP}$ regulates BMI1 ubiquitination and degradation (44). We next examined the effect of RASSF6 silencing on BMI1 stability in the presence of $\beta \operatorname{TrCP}$. RASSF6 silencing increased the upward-shifted BMI1 and delayed its degradation (Fig. 4F, right). Moreover, RASSF6 silencing reduced BMI1 polyubiquitination (Fig. 4G). We also examined the subcellular distribution of RASSF6 and BMI1 (see Fig. S3 in the supplemental material). RASSF6 did not affect the subcellular localization but reduced BMI1 expression. BMI1 also did not affect the subcellular localization of RASSF6. All these findings support the notion that RASSF6 promotes the degradation of BMI1, which may contribute to the enhancement of P16INK4A and P14ARF.

pRb is involved in RASSF6-induced apoptosis. Under certain circumstances, pRb is involved in apoptosis (45). For instance, in prostate cancer cells, cell detachment increases unphosphorylated $\mathrm{pRb}$ and induces apoptosis (46). Moreover, under DNA damage, pRb is dephosphorylated at CDK-mediated phosphorylation sites but phosphorylated by checkpoint kinases (47). Phosphorylated pRb binds to E2F1 and enhances proapoptotic genes (47). We first raised the question of whether $\mathrm{pRb}$ is involved in RASSF6-induced apoptosis. We expressed GFP-RASSF6 in HCT116 p53-/- cells. GFP-RASSF6 caused nuclear condensation and induced cytochrome $c$ release (Fig. $5 \mathrm{~A}$, siCont., GFP-RASSF6, arrows). RB1 silencing decreased nuclear condensation and cytochrome $c$ release (Fig. 5A, siRB1\#1 and siRB1\#2, GFP-RASSF6, arrowheads). In DNA content analysis by flow cytometry, GFP-RASSF6 increased the sub- $\mathrm{G}_{1}$ population (Fig. 5B, siCont., GFP and GFP-RASSF6). RB1 silencing, however, reduced the sub-G 1 population in RASSF6-expressing cells (Fig. 5B, siCont and siRB1\#1, GFP-RASSF6). These

FIG 4 Legend (Continued)

validation of BMI1 silencing was performed by qRT-PCR. (B) RASSF6 was immunoprecipitated from SW480 cells. The inputs and immunoprecipitates were immunoblotted with the indicated antibodies. The arrow indicates the coimmunoprecipitated BMI1. (C) HEK293FT cells were transfected with control pCIneoFHF (FLAG), pCIneoFHF-RASSF6 (FLAG-RASSF6), control pCIneoGFP (GFP), and pCIneoGFP-BMI1 (GFP-BMI1), as indicated. The immunoprecipitation was performed with either anti-DYKDDDDK (1E6) antibody beads (right) or anti-GFP antibody fixed on protein G-Sepharose 4 Fast Flow beads (left). The asterisk indicates the

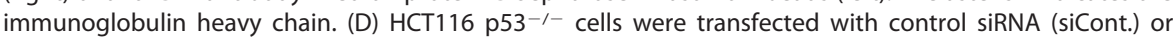
RASSF6 siRNA (siRASSF6\#2); $72 \mathrm{~h}$ later, the cells were treated with $50 \mathrm{mg} /$ /iter cycloheximide for $3 \mathrm{~h}$. Treatment with lambda phosphatase abolished the upper band. The samples were immunoblotted with the indicated antibodies, and endogenous BMI1 was detected. (E) HCT116 p53-1- cells were transfected with pCIneoGFP-RASSF6; $24 \mathrm{~h}$ later, the cells were treated with $50 \mathrm{mg} /$ liter cycloheximide and collected at the indicated time points. Endogenous BMI1 was immunoblotted. RASSF6 reduced phosphorylated BMI1 and

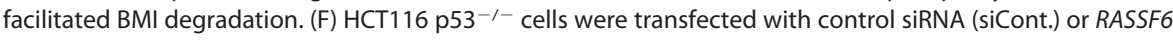
siRNA (siRASSF6\#1); $24 \mathrm{~h}$ later, the cells were transfected with pcDNA3-myc3- $\beta \operatorname{TrCP}$, and $48 \mathrm{~h}$ later, BMI1 degradation was evaluated as described for panel E. RASSF6 silencing increased phosphorylated BMI1 and delayed BMI1 degradation. (G) HEK293FT cells were transfected with control siRNA or RASSF6 siRNAs (\#1 and \#2); $24 \mathrm{~h}$ later, the cells were transfected with pCIneFH-BMI1 and pCGN-HA-UBC, and $48 \mathrm{~h}$ later, the cells were treated with $30 \mu \mathrm{M}$ MG-132 for $6 \mathrm{~h}$ and then lysed with the buffer containing guanidine hydrochloride. FH-BMI1 was isolated with Ni-NTA beads and immunoblotted with anti-HA antibody. RASSF6 silencing reduced BMI1 ubiquitination. 
A
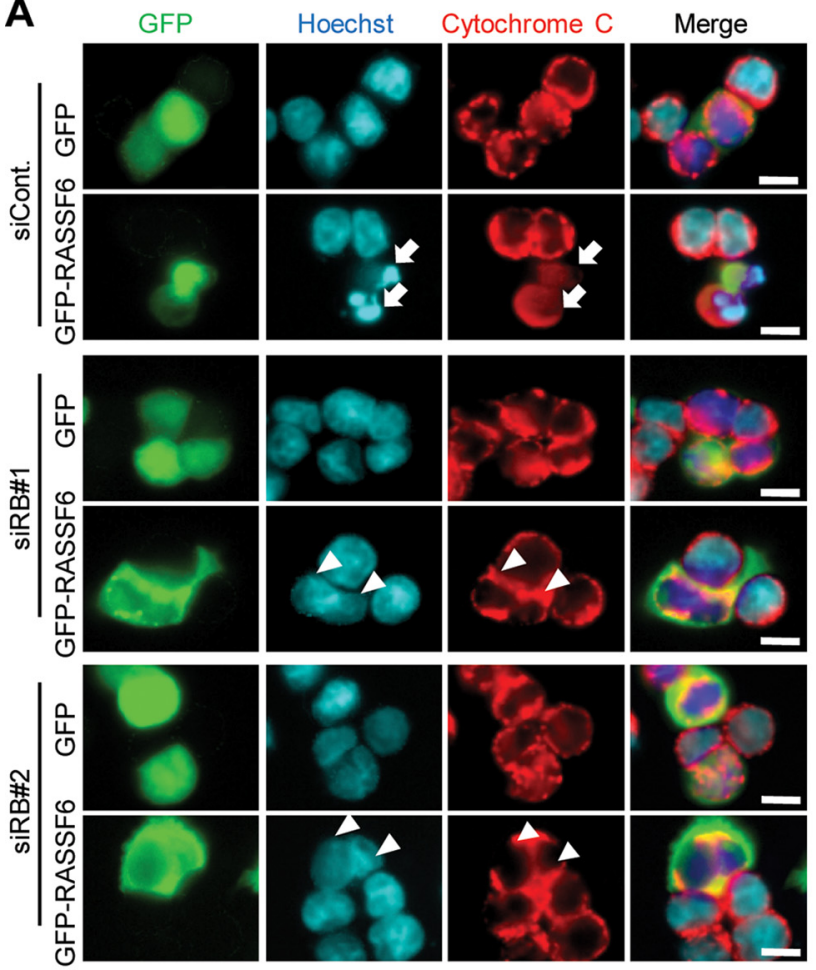

B

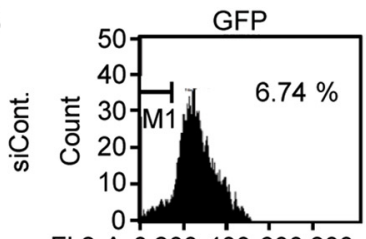

FL2-A 0200400600800

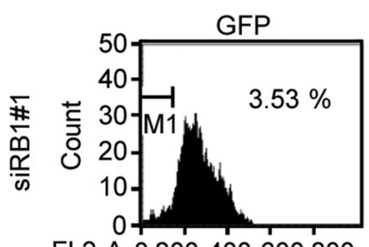

FL2-A 0200400600800

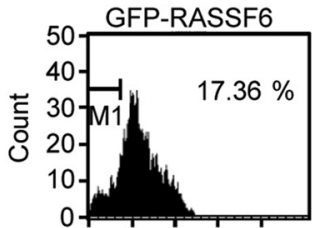

FL2-A 0200400600800

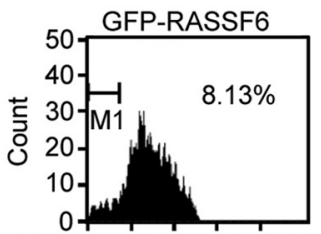

FL2-A 0200400600800

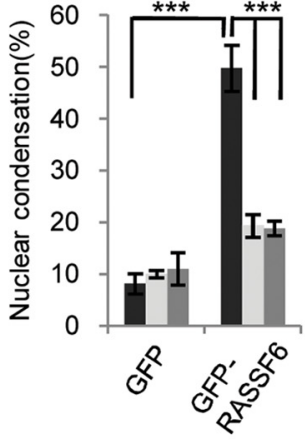

siCont.

SiRB1\#1

- siRB1\#2
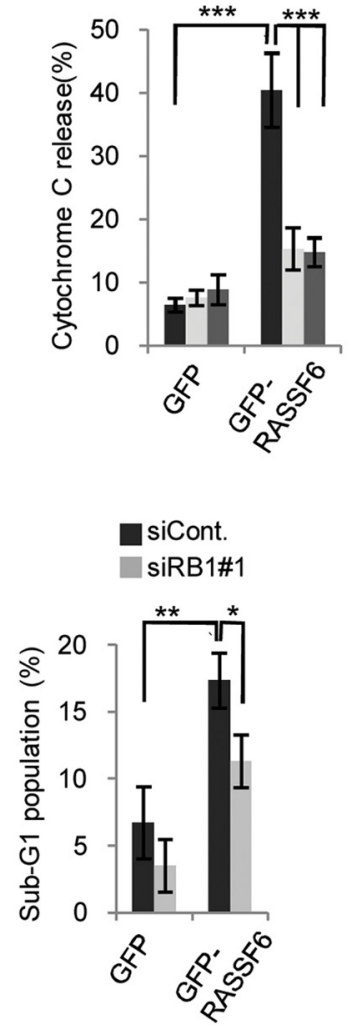

FIG 5 pRb is implicated in RASSF6-induced apoptosis in HCT116 p53-/- cells. HCT116 p53 ${ }^{-/-}$cells were transfected with control siRNA or RB1 siRNAs; $48 \mathrm{~h}$ later, the cells were replated on coverslips and transfected with control pCIneoGFP (GFP) or pCIneoGFP-RASSF6 (GFP-RASSF6). (A) Twenty-four hours later, the cells were immunostained with anti-cytochrome $c$ antibodies. The nuclei were visualized with Hoechst 33342. Fifty GFP-positive cells were observed, and the ratios of the cells with nuclear condensation and cytochrome $c$ release were calculated. GFP-RASSF6 induced nuclear condensation (arrows), but $R B 1$ silencing blocked it (arrowheads). The data are means with SD. ${ }^{* *}, P<0.001$. Scale bars, $10 \mu \mathrm{m}$. (B) The cells were fixed in ice-cold 70\% (vol/vol) ethanol, washed with PBS, and resuspended in PBS containing 10 mg/liter propidium iodide and $1 \mathrm{~g} /$ liter RNase $A$. The sub-G $\mathrm{G}_{1}$ population was evaluated with a FACSCalibur (BD Biosciences). The data were analyzed by use of BD CellQuest Pro Software. The data are means with SD. ${ }^{*}, P<0.05 ;{ }^{* *}, P<0.01$.

findings support the notion that pRb is involved in RASSF6-induced apoptosis in the p53-negative background.

E2F1 is involved in RASSF6-induced apoptosis. E2F1 regulates a wide variety of genes involved in not only proliferation but also apoptosis (48). For instance, E2F1 regulates apoptosis-related genes, such as $A P A F 1$ and $\operatorname{CASPS}(49,50)$. pRb recruits histone deacetylases to repress classic E2F1 target genes, such as CCNA2, but in cells exposed to DNA damage, pRb forms a transcriptionally active complex, including E2F1 

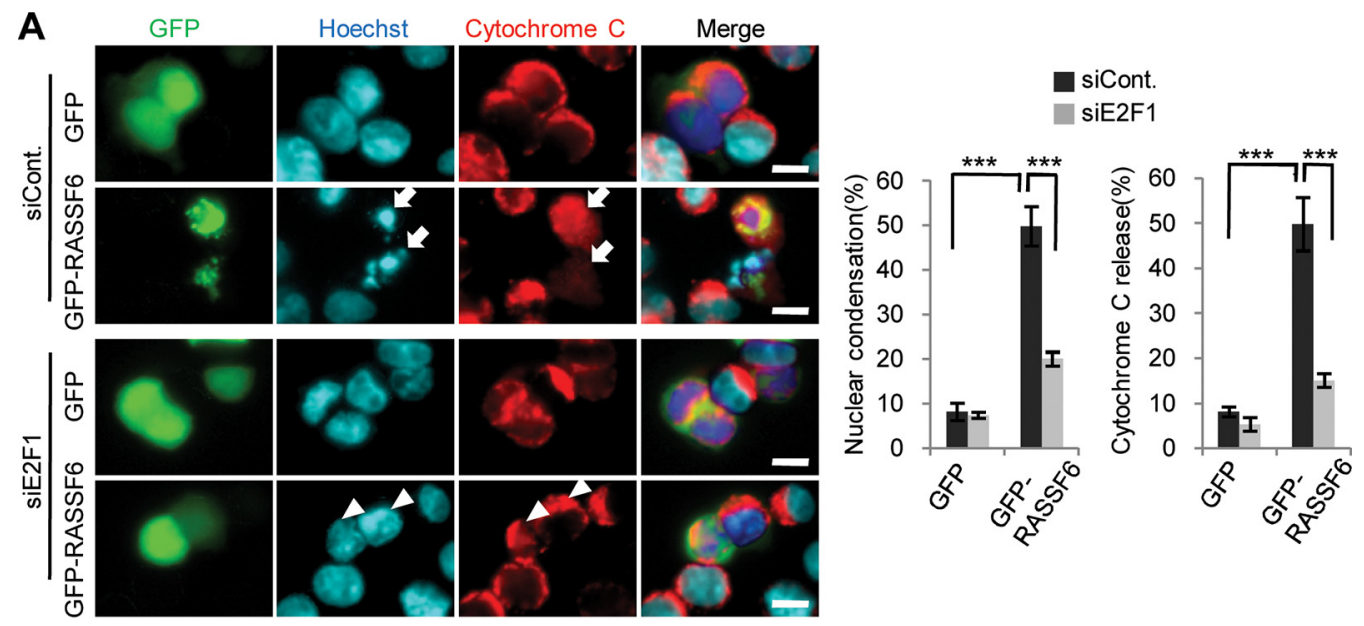

B
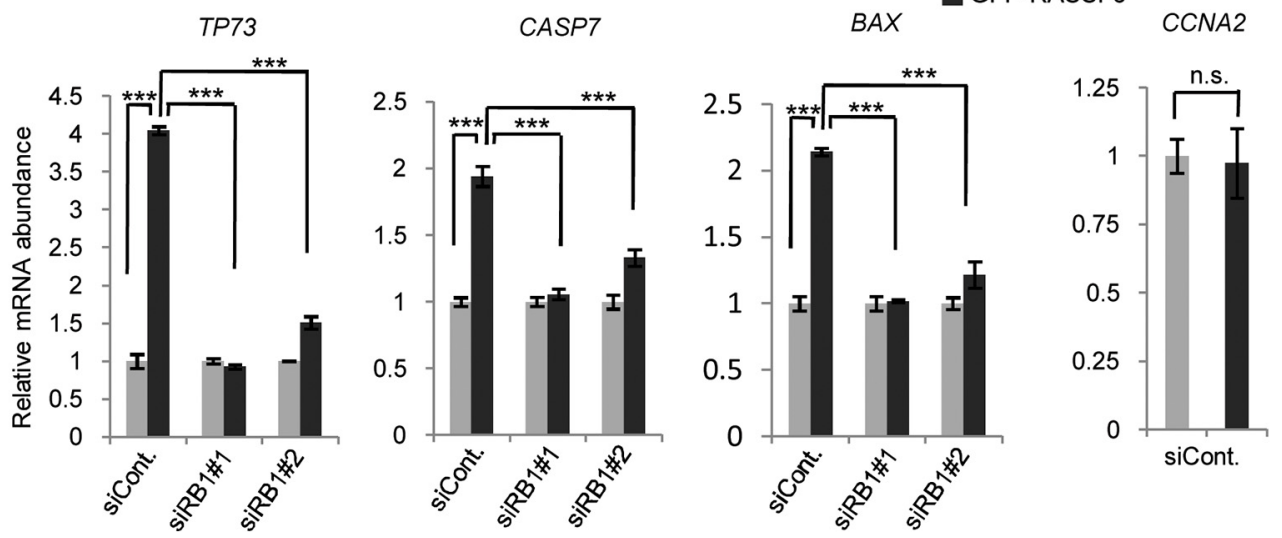

FIG 6 E2F1 is implicated in RASSF6-induced apoptosis in HCT116 p53-/- cells. (A) HCT116 p53-/- cells were transfected with control siRNA or E2F1 siRNA; $48 \mathrm{~h}$ later, the cells were replated on coverslips and transfected with control pCIneoGFP (GFP) or pCIneoGFP-RASSF6 (GFP-RASSF6). Apoptosis was evaluated as described for Fig. 5A. The data are means with SD. Arrows and arrowheads show induction and blockage of nuclear condensation and cytochrome $c$ release as described for Fig. 5A. ${ }^{* *}, P<0.001$. Scale bars, $10 \mu \mathrm{m}$. (B) HCT116 $\mathrm{p53} 3^{-/-}$cells were transfected with control siRNA, RB1 siRNA\#1, or E2F1 siRNA; $48 \mathrm{~h}$ later, the cells were transfected with control pCIneoGFP or pCIneoGFP-RASSF6, and $24 \mathrm{~h}$ later, the cells were harvested and mRNAs were collected. qRT-PCR was performed with glyceraldehyde-3-phosphate dehydrogenase as a reference. The value for the cells expressing control GFP was set at 1.0. The data are means with SD for the triplicate samples. TP73, CASP7, and BAX genes were upregulated by RASSF6. RB1 or E2F1 knockdown abolished the effect of RASSF6. The CCNA2 gene was not enhanced by RASSF6. ${ }^{* * *}, P<0.001$; n.s., not significant.

and P/CAF, to promote transcription of proapoptotic genes, such as TP73 and CASP7 $(47,51,52)$. To determine whether E2F1 is involved in RASSF6-induced apoptosis, we examined the effect of E2F1 silencing. E2F1 silencing attenuated RASSF6-induced nuclear condensation and cytochrome $c$ release in RASSF6-expressing HCT116 p53-/cells (Fig. 6A). To more directly confirm that RASSF6 plays a role in pRb/E2F1-mediated transcription of proapoptotic genes, we quantified mRNAs of TP73, CASP7, and BAX. RASSF6 increased proapoptotic TP73, CASP7, and BAX but had no effect on CCNA2 (Fig. $6 \mathrm{~B}$, siCont). However, RB1 silencing and E2F1 silencing abolished the effect of RASSF6 (Fig. 6B, siRB1\#1 and siE2F1). These findings support the notion that E2F1 is involved in RASSF6-induced apoptosis. Although YAP1, a target of the Hippo pathway, cooperates with p73, YAP1 silencing had no effect on RASSF6-mediated apoptosis in HCT116 $\mathrm{p} 53^{-1-}$ cells (see Fig. S4 in the supplemental material). BMI1 silencing also did not augment RASSF6-induced apoptosis (see Fig. S5 in the supplemental material).

RASSF6 depletion impairs DNA repair and causes genomic instability. In the previous study, we demonstrated that RASSF6 depletion impairs DNA repair in HCT116 cells and results in the generation of polyploid cells (14). To evaluate the significance 
A

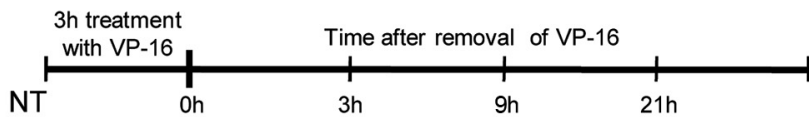

HCT116 p53+/+

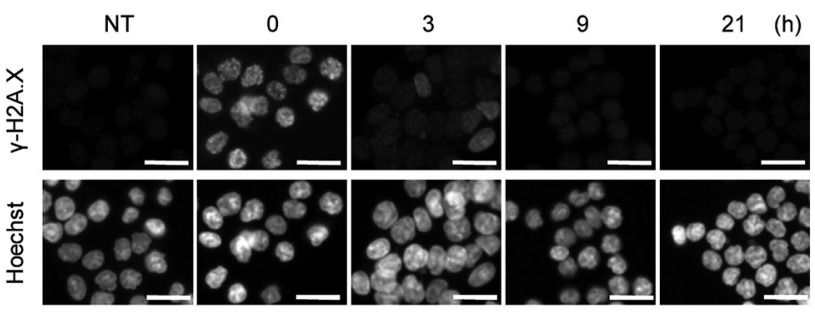

HCT116 p53-/

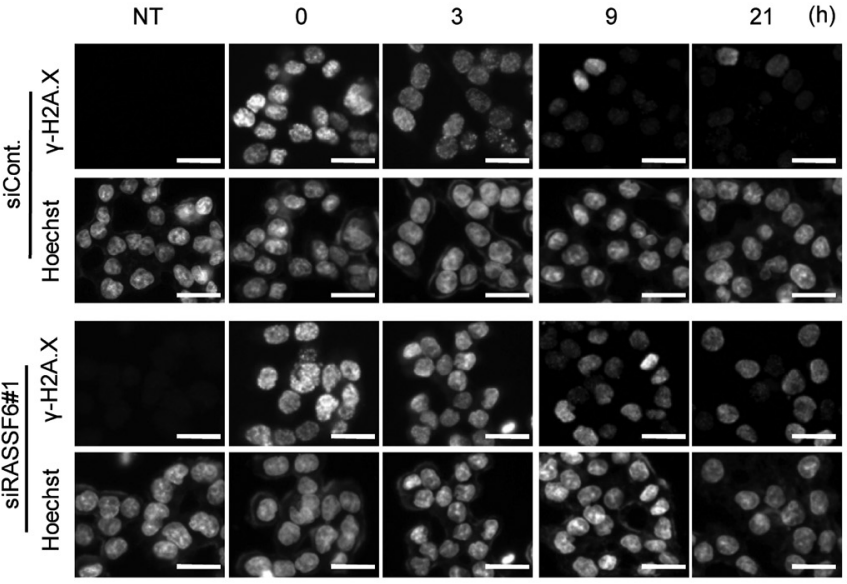

siCont.

口iRASSF6\#1

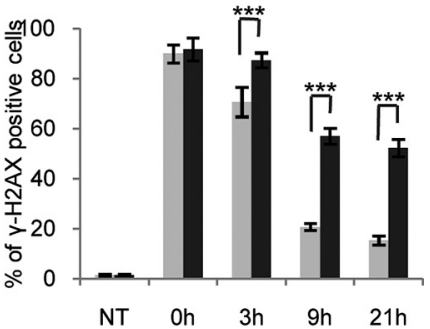

siCont

siRASSF6\#1

- siRASSF6\#2

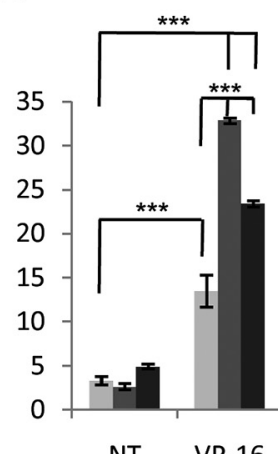

B

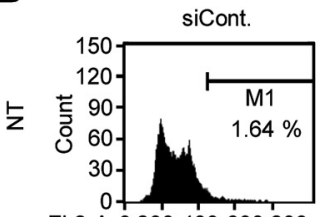

FL2-A 0200400600800

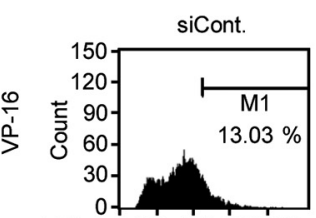

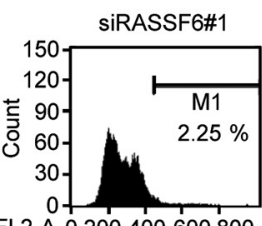

SiRASSF6\#1

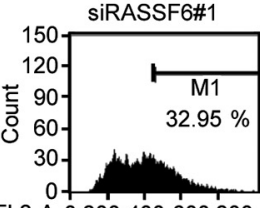

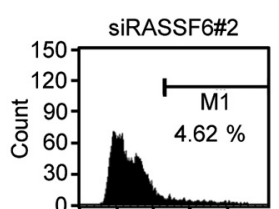

FL2-A 0200400600800

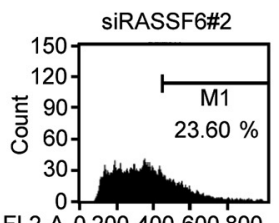

FL2-A 0200400600800 FL2-A 0200400600800 FL2-A 0200400600800

FIG 7 RASSF6 depletion delays DNA repair and increases polyploid cells in a p53-negative background. HCT116 p53+/+ cells were exposed to $50 \mu \mathrm{M}$ VP-16 for $3 \mathrm{~h}$, and then VP-16 was removed. The cells were harvested at the indicated times, and $\gamma \mathrm{H} 2 \mathrm{~A}$.X was immunostained. A scheme of the protocol is shown at the top of panel A. (A and B) HCT116 p53 ${ }^{-1-}$ cells were transfected with control siRNA or RASSF6 siRNA (\#1 [A] or \#1 and \#2 [B]); $48 \mathrm{~h}$ later, the cells were exposed to $50 \mu \mathrm{M}$ VP-16 for $3 \mathrm{~h}$, and then, VP-16 was removed. (A) Thereafter, $\gamma \mathrm{H} 2 \mathrm{~A}$.X was immunostained at the indicated times $(0 \mathrm{~h}$ means immediately after 3-h treatment with VP-16), and $\gamma \mathrm{H} 2 \mathrm{~A} . \mathrm{X}$ was immunostained. Five hundred cells were observed for each sample, and $\gamma \mathrm{H} 2 \mathrm{~A}$.X-positive cells were counted. The bar graphs are summaries of the results of three independent experiments. The data are means with SD. ${ }^{* * *}, P<0.001$. Scale bars, $20 \mu \mathrm{m}$. (B) Cells were cultured for $96 \mathrm{~h}$ after removal of VP-16, and DNA contents were evaluated by FACS. VP-16 treatment induced polyploid cells, and RASSF6 depletion further increased them.

of RASSF6 as a tumor suppressor in a p53-negative background, we examined the effect of RASSF6 depletion on DNA repair in HCT116 p53-/- cells. After $3 \mathrm{~h}$ of treatment with VP-16, $\gamma \mathrm{H} 2 \mathrm{~A} . \mathrm{X}$ signals appeared (Fig. 7A, HCT116 p53+/+, 0 h) but disappeared within $3 \mathrm{~h}$ after the removal of VP-16 in HCT116 p53 $3^{+/+}$cells (Fig. 7A, HCT116 p53+/+, $3 \mathrm{~h}$ ). However, in HCT116 p53-/- cells, the signals remained for up to $9 \mathrm{~h}$ (Fig. $7 \mathrm{~A}$, $\mathrm{HCT} 116 \mathrm{p} 53^{-/-}$, siCont, $9 \mathrm{~h}$ ). This means that DNA repair is delayed in $\mathrm{HCT} 116 \mathrm{p} 53^{-/-}$ 
cells. Even so, $\gamma \mathrm{H} 2 \mathrm{~A} . \mathrm{X}$ signals decreased in a time-dependent manner and became barely detectable $21 \mathrm{~h}$ later (Fig. 7A, HCT116 p53-/-, siCont, 21 h). However, when RASSF6 was suppressed, $\gamma \mathrm{H} 2 \mathrm{~A} . \mathrm{X}$ signals were still visible at $21 \mathrm{~h}$ (Fig. 7A, HCT116 p53 $3^{-1-}$, siRASSF6\#1, $21 \mathrm{~h}$ ). These findings support the notion that RASSF6 is necessary for DNA repair in a p53-negative background. We cultured VP-16-treated HCT116 p53 $3^{-1-}$ cells for $96 \mathrm{~h}$ and analyzed the DNA content by fluorescence-activated cell sorting (FACS). The polyploid cells were increased by the treatment with VP-16 (Fig. 7B, siCont, $1.64 \%$ versus $13.03 \%$ ). RASSF6 depletion further increased the polyploid cells (Fig. 7B, VP-16, siRASSF6\#1 and siRASSF6\#2). All these findings support the possibility that RASSF6 plays a tumor suppressor role in cancer cells with dysregulated p53.

\section{DISCUSSION}

RASSF6 is one of the classical RASSF proteins, which have Ras association domains in the C-terminal region, and cooperates with the well-conserved tumor suppressor Hippo pathway (41). The low expression of RASSF6 is observed in human cancers and correlates with shortened disease-free survival, which corroborates the notion that RASSF6 plays a tumor-suppressive role in humans. Forced expression of RASSF6 induces apoptosis and cell cycle arrest in various cells $(11,12)$. p53 depletion attenuates RASSF6-induced apoptosis and overcomes RASSF6-induced cell cycle arrest, which supports the notion that p53 functions downstream of RASSF6 (14). In fact, RASSF6 interacts with MDM2 and blocks MDM2-mediated degradation of p53. RASSF6 depletion suppresses UV exposure-induced p53 target gene expression. KRAS strengthens the interaction between RASSF6 and MDM2 and causes apoptosis by enhancing p53 expression (19). In this respect, MDM2-p53 is important for the tumor suppressor role of RASSF6. However, p53 depletion does not completely abolish RASSF6-mediated apoptosis (14). Moreover, RASSF6 induces apoptosis in p53-negative HCT116 cells. These findings imply that RASSF6 causes apoptosis independently of p53. This observation is important, because it means that RASSF6 works as a tumor suppressor in cancers with p53 mutations. In this line, we have studied the molecular mechanism underlying the p53-independent tumor suppressor role of RASSF6.

$R B 1$ is the first identified tumor suppressor gene, and its defects cause many human cancers (23). A recent report has revealed that Nore1A (a splicing variant of RASSF5) forms a complex composed of protein phosphatase $1 \mathrm{~A}$ and $\mathrm{pRb}$ to promote $\mathrm{pRb}$ dephosphorylation and to mediate Ras-induced senescence (39). Based on these data, we examined the relations of RASSF6 and pRb. To accentuate the role of $p R b$, we used HCT116 $\mathrm{p} 53^{-1-}$ cells in this study. First, we confirmed that RB1 silencing attenuates RASSF6-induced cell cycle arrest (Fig. 1).

Unphosphorylated pRb binds and inhibits the E2F family transcription factors (20, 26). When $\mathrm{pRb}$ is phosphorylated by CDKs, it fails to bind the E2F proteins, so that cells proceed from $G_{1}$ to enter $S$. From $M$ to $G_{1}, p R b$ is dephosphorylated by protein phosphatases and returns to the unphosphorylated form (35). As RASSF6 blocks DNA synthesis depending on pRb (Fig. 1) and Nore1 A promotes pRb dephosphorylation (39), we suspected that RASSF6, as well, suppresses the phosphorylation of pRb. As expected, RASSF6 reduces phosphorylation at serine 608 and at threonine 821, both of which destabilize the interaction between pRb and E2F (Fig. 2). Accordingly, RASSF6 strengthens the binding of pRb to E2F1 and suppresses the E2F1 promoter reporter, depending on pRb (Fig. 2D and E). Conversely, RASSF6 silencing enhanced the E2F1 promoter reporter (Fig. 2F). A kinase short hairpin RNA (shRNA) screening revealed that LATS2 promotes the assembly of the DREAM repressor complex and suppresses E2F target genes (34). As RASSF6 cross talks with the Hippo pathway, it is reasonable to ask whether LATS2 is implicated in RASSF6-mediated suppression of E2F1 reporter activity. However, LATS1-LATS2 silencing had no effect (Fig. 2G). Moreover, LIN52 silencing also did not affect RASSF6-mediated repression (Fig. 2H). These findings suggest that RASSF6 represses E2F1-mediated transcription independently of the DREAM repressor complex. Likewise, YAP1 silencing did not show any effect on RASSF6-mediated apop- 


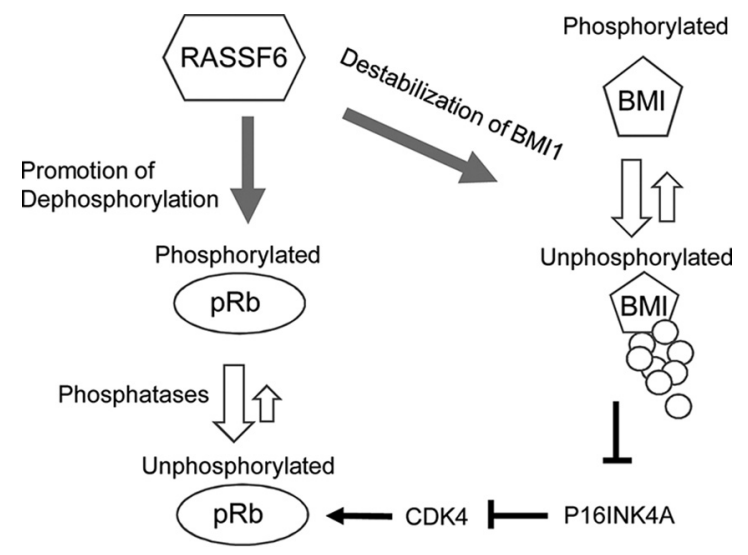

FIG 8 Mechanism by which RASSF6 keeps pRb unphosphorylated. RASSF6 links protein phosphatases to $\mathrm{pRb}$ and promotes dephosphorylation of pRb. RASSF6 also reduces the phosphorylated form of BMI1, which is resistant to $\beta \operatorname{TrCP}$-mediated degradation, eventually destabilizes BMI1, and increases P16INK4A, which in turn inhibits CDK4.

tosis (see Fig. S4 in the supplemental material). This result is comprehensible, because RASSF6 plays a tumor suppressor role independently of the Hippo pathway (12).

As reported for Nore1A, RASSF6 increases the interaction between $\mathrm{pRb}$ and protein phosphatases. RASSF6 and pRb were coimmunoprecipitated (Fig. $3 A$ and B), and pRb recruited RASSF6 into the nucleus (Fig. $3 C$ and D). These findings support the notion that RASSF6 and pRb interact with each other. Considering that proteomic analysis revealed RASSF proteins in the interactome of MST kinases and the STRIPAK complex, we speculated that RASSF6 may link protein phosphatases to pRb. Indeed, RASSF6 promoted the binding of PP1A and PP2A to pRb (Fig. 3E). RASSF6 interacts with other RASSF proteins (41), and RASSF5 promotes dephosphorylation of pRb via PP1A (39). Conversely, RASSF1A blocks PP1- and PP2A-mediated dephosphorylation of mammalian Ste20-like kinases 1 and 2 (40). Therefore, it is possible that RASSF6 modulates the phosphorylation of pRb via RASSF1A and RASSF5. However, RASSF1 silencing or RASSF5 silencing did not affect the inhibitory effect of RASSF6 on the E1F1 promoter reporter, which indicates that RASSF6 regulates pRb independently of RASSF1 or RASSF5 (see Fig. $\mathrm{S} 1$ in the supplemental material).

We also found that RASSF6 increases P16INK4A and P14ARF expression in a p53negative background. RASSF6 promotes the degradation of BMI1, which suppresses P16INK4A and P14ARF. Serine 110 phosphorylation is known to stabilize BMI1 (53). RASSF6 is considered to promote the dephosphorylation of BMI1 and to destabilize it. We also observed that CDKN1A expression was enhanced by doxorubicin in HCT116 p53 ${ }^{-1-}$ cells, which is consistent with a previous report (54), but that RASSF6 silencing had no effect on CDKN1A. In that paper, the researchers demonstrated that p63 was implicated. Thus, the induction of CDKN1A by doxorubicin in HCT116 p53-1- cells may be independent of RASSF6. In short, RASSF6 reduces the phosphorylation of pRb in two ways: through the promotion of dephosphorylation and the inhibition of phosphorylation by CDKs (Fig. 8).

In cells exposed to DNA damage, such as doxorubicin treatment, phosphorylated $\mathrm{pRb}$ forms a complex with E2F1 (47). DNA damage triggers the binding of histone acetyltransferase to E2F1 and the acetylation of E2F1 and promotes the association of E2F1 with the promoters of proapoptotic genes. Therefore, we examined whether pRb and E2F1 are implicated in RASSF6-induced apoptosis. The silencing of RB1 or E2F1 suppresses RASSF6-induced apoptosis (Fig. 5 and 6). RASSF6 expression enhances proapoptotic genes, including TP73, CASP7, and BAX, while the silencing of RB1 or E2F1 blocks the effect of RASSF6 (Fig. 6). We previously observed that TP73 silencing did not attenuate RASSF6-induced apoptosis in HCT116 p53+/+ cells (14). Therefore, the enhancement of TP73 by RASSF6 was unexpected. However, it has been reported that p73 
functionally replaces p53 in p53-deficient cells (55). As we used HCT116 p53-/- cells in this study, we speculate that the transcriptional regulatory networks may be changed by $\mathrm{p} 53$ depletion in these cells.

In the final set of experiments, we showed that RASSF6 depletion impairs DNA repair in p53-negative cells (Fig. 7). RASSF6 depletion also increases the generation of polyploid cells. These findings suggest that RASSF6 is a significant tumor suppressor in p53-compromised cells. Of note, RB1 silencing did not completely abolish RASSF6induced apoptosis in p53-negative cells (Fig. 5). RASSF6 induces apoptosis and suppresses proliferation in Saos- 2 cells, which have TP53 mutation and RB1 mutation (data not shown). These findings mean that there should be a specific mechanism by which RASSF6 works as a tumor suppressor independently of both p53 and pRb. The dissection of such a mechanism will be the subject of future research.

\section{MATERIALS AND METHODS}

DNA construction and virus production. pCIneoGFP, pClneoFH, pClneoMyc, pCIneoFHF-RASSF6, pCIneoMyc-RASSF6, pCIneoGFP-RASSF6, pCIneoLuc-PP1A, pCIneoLuc-PP2A, pLenti-EF-ires-blast, and pCIneoHAHA-MDM2 have been described previously $(11,12,14,56)$. pLX304-pRb-V5 was derived from the CCSB-Broad Lentiviral Expression Library (GE Healthcare Dharmacon Inc.). An Nhel/Sall fragment from pCIneoFHF-RASSF6 was ligated into the Spel/Xhol sites of pLenti-EF-ires-blast to generate pLenti-EFFHF-RASSF6-ires-blast. pcDNA E2F1 was a gift from Masa-Aki lkeda (Tokyo Medical and Dental University). PCR was performed with primers H3086 (5'-GAATTCATGGCCTTGGCCGGGGCC-3') and H3087 (5'-GATA TCAGAAATCCAGGGGGGTGAG-3') on pCDNA E2F1, and the product was digested with EcoRI/EcoRV and ligated into the EcoRI/Smal sites of pClneoFH to generate pCIneoFH-E2F1. pCGN-HA-Ubc was a gift from Akira Kikuchi (Osaka University). Human BMI1 CDNA was obtained by PCR using the primers $\mathrm{H}-2539$ (5'-ACGCGTATGCATCGAACAACGAGAAT-3') and H-2540 (5'-GTCGACTCAACCAGAAGAAGTTGCTG-3') and human lung and kidney cDNA libraries as the template. The PCR product was cloned into the Mlul/Sall sites of pCIneoGFP to generate pCIneoGFP-BMI1. pcDNA3-myc3- $\beta \operatorname{TrCP}$ was a gift from Yue Xiong (Addgene; plasmid number 20718) (57).

Antibodies and reagents. The following antibodies and reagents were obtained from commercial sources: rabbit anti-GFP (598) and rat antihemagglutinin (anti-HA) (561; Medical and Biological Laboratories Co. Ltd., Nagoya, Japan); mouse anti- $\beta$-actin (A1978), pepstatin A (P5318), doxorubicin (D-1515), and Hoechst 33342 (Sigma-Aldrich, St. Louis, MO); anti-DYKDDDDK tag (014-22383), anti-DYKDDDDK tag beads (016-22784), anti-V5 tag beads (016-24381), Phos-tag acrylamide, and leupeptin (334-40414) (Wako Pure Chemical Industries, Osaka, Japan); MG-132 (Nakalai Tesque, Tokyo, Japan); VP-16 (E0675) (Tokyo Medical Industry, Tokyo, Japan); lambda phosphatase (sc-200312; Santa Cruz Biotechnology, Dallas, TX); Picagene (Toyo Ink); rabbit polyclonal anti-V5 tag (PM003; Medical \& Biological Laboratories Co. Ltd., Nagoya, Japan); rabbit anti-RASSF6 (11921-1-AP; Proteintech, Rosemond, IL); protein G-Sepharose 4 Fast Flow (GE Healthcare, Little Chalfont, United Kingdom); mouse anti-cytochrome c $(6 \mathrm{H} 2$ B4) (556432), mouse anti-human Rb (554136), and mouse anti-underphosphorylated-Rb (554164) (BD Biosciences, San Jose, CA); mouse anti-Myc (9E10; American Type Culture Collection, Manassas, VA); rabbit polyclonal anti-phospho-Rb (Ser608) (2181) and rabbit polyclonal anti-phospho-Rb (Ser807/811) (9308) (Cell Signaling Technology, Danvers, MA); mouse monoclonal anti-Bmi-1 (05-637) and antiphospho-histone H2A.X (Ser139) (JBW341) (Merck, Kenilworth, NJ); and rabbit polyclonal antiphospho-Rb (Thr821) (44-582G; Thermo Fisher Scientific, Waltham, MA).

Cell cultures, transfection, and infection. HEK293FT, HCT116, HCT116 p53-/-, and HeLa cells were cultured in Dulbecco's modified Eagle medium containing 10\% (vol/vol) fetal bovine serum and $10 \mathrm{mM}$ HEPES-NaOH, pH 7.4, under $5 \% \mathrm{CO}_{2}$ at $37^{\circ} \mathrm{C}$. Transfection was performed with Lipofectamine 2000 (Thermo Fisher Scientific, Waltham, MA). HEK293FT cells were transfected with pLenti-EF-FHF-RASSF6 and packaging plasmids to generate the lentivirus vector.

Immunoprecipitation of RASSF6 from SW480 cells. SW480 cells at 50 to $60 \%$ confluence in two $100-\mathrm{mm}$ dishes were suspended in $1 \mathrm{ml}$ of phosphate-buffered saline (PBS) supplemented with 50 $\mu \mathrm{M} p$-(amidinophenyl)methanesulfonyl fluoride (APMSF), $10 \mathrm{mg} /$ liter leupeptin, $3 \mathrm{mg} /$ liter pepstatin A and lysed by sonication at high power 3 times for $10 \mathrm{~s}$ each time, with 1-min intervals. The lysates were centrifuged at $20,000 \times g$ for $10 \mathrm{~min}$ at $4^{\circ} \mathrm{C}$. The supernatant was incubated with $1 \mu \mathrm{g}$ of rabbit anti-RASSF6 antibody or control rabbit $\lg$ overnight at $4^{\circ} \mathrm{C}$ and further incubated with protein $\mathrm{G}$-Sepharose 4 Fast Flow beads (GE Healthcare) for $2 \mathrm{~h}$ at $4^{\circ} \mathrm{C}$. The beads were washed four times with PBS, and the precipitates were analyzed by SDS-PAGE and immunoblotting.

Coimmunoprecipitation for exogenously expressed proteins. HEK293FT cells were plated at $1 \times$ $10^{6}$ cells/well in a 6-well plate; $24 \mathrm{~h}$ later, the indicated plasmids were transfected with Lipofectamine 2000. Forty-eight hours later, the cells were treated with either $10 \mu \mathrm{M}$ epoxomicin or $10 \mu \mathrm{M} \mathrm{MG}-132$ for $6 \mathrm{~h}$ and then harvested. The cells were lysed in $500 \mu \mathrm{l}$ of lysis buffer $(25 \mathrm{mM}$ Tris- $\mathrm{HCl}, \mathrm{pH} 7.4,100 \mathrm{mM}$ $\mathrm{NaCl}, 1 \mathrm{mM}$ EDTA, $1 \mathrm{mM}$ EGTA, 0.5\% [wt/vol] sodium deoxycholate, 1\% [vol/vol] Triton X-100, $50 \mu \mathrm{M}$ APMSF, $3 \mathrm{mg} /$ /iter pepstatin A, $10 \mathrm{mg} /$ /iter leupeptin, $50 \mathrm{mM} \mathrm{NaF}, 2 \mathrm{mM} \mathrm{Na}_{3} \mathrm{VO}_{4}$, and $10 \mu \mathrm{M} \mathrm{MG}-132$ ) and centrifuged at 20,000 $\times g$ for $10 \mathrm{~min}$. The supernatant (input) was incubated with $5 \mu \mathrm{l}$ of anti-DYKDDDDK tag beads, anti-V 5 tag beads, or anti-GFP antibody fixed on protein G-Sepharose 4 Fast Flow beads. The beads were washed with the lysis buffer. The proteins in the inputs and in the immunoprecipitates were detected with antibodies. For the Lumier assay, we used luciferase-fused proteins and measured 
TABLE 1 Primers for qRT-PCR

\begin{tabular}{|c|c|c|}
\hline Primer & Orientation $^{a}$ & Sequence \\
\hline \multirow[t]{2}{*}{$\overline{\mathrm{RB} 1}$} & $\mathrm{~F}$ & GAACATCGAATCATGGAATCCCT \\
\hline & $\mathrm{R}$ & AGAGGACCAGCAGATTCAAGGTGAT \\
\hline \multirow[t]{2}{*}{ E2F1 } & $\mathrm{F}$ & ATGTITCCTGTGCCCTGAG \\
\hline & $\mathrm{R}$ & ATCTGTGGTGAGGGATGAGG \\
\hline \multirow[t]{2}{*}{ RASSF6 } & $\mathrm{F}$ & ACGTCTTCTCCAGCAAAGGA \\
\hline & $\mathrm{R}$ & CAGAGCTGCTTCACTCATGG \\
\hline \multirow{2}{*}{ CDKN1A } & $\mathrm{F}$ & GGCAGACCAGCATGACAGATT \\
\hline & $\mathrm{R}$ & GCGGATTAGGGCTTCCTCTT \\
\hline \multirow[t]{2}{*}{ P16INK4A } & $\mathrm{F}$ & AACGCACCGAATAGTTACGGT \\
\hline & $\mathrm{R}$ & CTGCCCATCATCATGACCT \\
\hline \multirow[t]{2}{*}{ P14ARF } & $\mathrm{F}$ & AGGGTTTTCGTGGTTCACAT \\
\hline & $\mathrm{R}$ & CTGCCCATCATCATGACCT \\
\hline \multirow[t]{2}{*}{ TP73 } & $\mathrm{F}$ & CCCACCACTITGAGGTCACT \\
\hline & $\mathrm{R}$ & GGCGATCTGGCAGTAGAGTT \\
\hline \multirow[t]{2}{*}{ CASP7 } & $\mathrm{F}$ & GCAGTGGGATTTGTGCTTCT \\
\hline & $\mathrm{R}$ & CCCTAAAGTGGGCTGTCAAA \\
\hline \multirow[t]{2}{*}{ BAX } & $\mathrm{F}$ & ATGTTITTCTGACGGCAACTTC \\
\hline & $\mathrm{R}$ & ATCAGTTCCGGCAACCTTG \\
\hline \multirow[t]{2}{*}{ CCNA2 } & $\mathrm{F}$ & TCCATGTCAGTGCTGAGAGGA \\
\hline & $\mathrm{R}$ & GAAGGTCCATGAGACAAGGC \\
\hline \multirow[t]{2}{*}{ GAPDH } & $\mathrm{F}$ & ССАСТCCTCCACCTTTGAC \\
\hline & $\mathrm{R}$ & ACCCTGTTGCTGTAGCCA \\
\hline \multirow[t]{2}{*}{ BMI1 } & $\mathrm{F}$ & GGCTCTAATGAAGATAGAGGAG \\
\hline & $\mathrm{R}$ & TCACAGTCATTGCTGCTGGGCA \\
\hline \multirow[t]{2}{*}{ RPS18 } & $\mathrm{F}$ & TTTGCGAGTACTCAACACCAA \\
\hline & $\mathrm{R}$ & GCATATCTTCGGCCCACA \\
\hline \multirow[t]{2}{*}{ RASSF1A } & $\mathrm{F}$ & GACTCTGGGGAGGTGAACTG \\
\hline & $\mathrm{R}$ & GGAGTACTTCTGCAGGATCTGG \\
\hline \multirow[t]{2}{*}{ RASSF5 } & $\mathrm{F}$ & GACAGCTACAACACGCGAGA \\
\hline & $\mathrm{R}$ & AGGGGCAGGTAGAAGGATGT \\
\hline \multirow[t]{2}{*}{ LATS1 } & $\mathrm{F}$ & GTCCTTCGTGTGGGCTACAT \\
\hline & $\mathrm{R}$ & CGAGGATCTTCGGTTGACAT \\
\hline \multirow[t]{2}{*}{ LATS2 } & $\mathrm{F}$ & TTCATCCACCGAGACATCAA \\
\hline & $\mathrm{R}$ & CTCCATGCTGTCCTGTCTGA \\
\hline \multirow[t]{2}{*}{ YAP1 } & $\mathrm{F}$ & CAGCACAGCAAATTCTCCAA \\
\hline & $\mathrm{R}$ & TGGATITTGAGTCCCACCAT \\
\hline \multirow[t]{2}{*}{ LIN52 } & $\mathrm{F}$ & CGAGGCCTACAGAACCTAGC \\
\hline & $\mathrm{R}$ & ATTTCCCCCGTGTCATCTC \\
\hline
\end{tabular}

${ }^{a}$, forward; $\mathrm{R}$, reverse.

luciferase activity in the immunoprecipitates by the use of Picagene (Toyo INK, Tokyo, Japan) as a substrate (56).

Subcellular fractionation. Cells at 70 to $80 \%$ confluence in $60-\mathrm{mm}$ dishes were washed with ice-cold PBS and harvested by scraping. The cells were collected by centrifugation at $4^{\circ} \mathrm{C}$, resuspended with 200 $\mu \mathrm{l}$ of hypotonic buffer $\left(10 \mathrm{mM}\right.$ HEPES-NaOH, pH 7.5, $10 \mathrm{mM} \mathrm{KCl}, 1.5 \mathrm{mM} \mathrm{MgCl}{ }_{2}, 0.34 \mathrm{M}$ sucrose, $10 \%$ [vol/vol] glycerol, $0.05 \%$ [vol/vol] Nonidet P-40, $50 \mathrm{mM}$ APMSF, $10 \mathrm{mg} /$ liter leupeptin, $3 \mathrm{mg} / \mathrm{liter}$ pepstatin, $50 \mathrm{mM} \mathrm{NaF}, 2 \mathrm{mM} \mathrm{Na} \mathrm{VO}_{4}$, and $25 \mathrm{mM} \beta$-glycerophosphate), and kept at $4^{\circ} \mathrm{C}$ for $5 \mathrm{~min}$. The cells were then resuspended by pipetting. After $66.6 \mu \mathrm{l}$ of the mixture was saved as the whole-cell lysate, the remaining samples were centrifuged at $800 \times g$ at $4^{\circ} \mathrm{C}$ for $5 \mathrm{~min}$. The supernatant was centrifuged 
again at $20,000 \times g$ for $10 \mathrm{~min}$ at $4^{\circ} \mathrm{C}$, and $90 \mu$ lof the supernatant was collected as the cytosolic fraction. The pellet was washed twice with hypotonic buffer, suspended with $133.3 \mu$ l of the same buffer, and used as the nuclear fraction.

Monitoring active DNA synthesis. Active DNA synthesis was evaluated by use of a Click-iT Edu Alexa Fluor 488 imaging kit (C10337; Thermo Fisher Scientific) according to the manufacturer's protocol.

Apoptosis. GFP-RASSF6 proteins were expressed in HCT116 p53-1- cells. The cells were immunostained with anti-cytochrome $c$ antibody, and the nuclei were visualized with Hoechst 33342 . The cytochrome $c$ release and nuclear condensation were evaluated. Detection of the sub- $\mathrm{G}_{1}$ population was performed by FACS, as described previously (14).

RNA interference. RNA interference was performed by use of Lipofectamine RNAiMax (Thermo Fisher Scientific). The following small interfering RNAs (siRNAs) were obtained from Thermo Fisher Scientific: Silencer Select negative control no.2, human RASSF6 no. 1 (s46640) and no. 2 (s46639), human E2F1 (s4405), human RB1 no. 1 (s523) and no. 2 (s522), human BMI1 (s2015), human LATS1 (s17392), human LATS2 (s25505), human RASSF1 (s22088), human RASSF5 (s38021), and human YAP1 no. 1 (s20366) and no. 2 (s20367). Human LIN52 (sc-92126) was obtained from Santa Cruz Biotechnology.

Quantitative RT-PCR. Quantitative reverse transcription (qRT)-PCR was performed in HCT116 p53-1cells as described previously (14). The primers are listed in Table 1.

Reporter assay. For the E2F1 reporter assay, HEK293FT cells were transfected with the E2F1-Luc (-242) reporter (a gift from Masa-Aki Ikeda, Tokyo Medical and Dental University) and pCMV alkaline phosphatase (a gift from Sumiko Watanabe, the University of Tokyo). Luciferase activity was assayed as described previously (58).

Treatment with lambda phosphatase. HCT116 p53-1- cells were plated at $4 \times 10^{5}$ cells in a $60-\mathrm{mm}$ dish and transfected with control siRNA or RASSF6 siRNA; $72 \mathrm{~h}$ later, the cells were treated with 50 $\mathrm{mg} /$ liter cycloheximide for $3 \mathrm{~h}$. Then, the cells were collected and lysed in $200 \mu \mathrm{l}$ of the above-described lysis buffer. The lysates were centrifuged at 20,000 $\times \mathrm{g}$ for $10 \mathrm{~min}$, and 200 units (0.5 ml) of lambda protein phosphatase, $5 \mathrm{ml}$ of $10 \times$ lambda phosphatase buffer (500 mM HEPES-NaOH [pH 7.5], $1 \mathrm{mM}$ EGTA, $50 \mathrm{mM}$ dithiothreitol, and $0.1 \%$ Brij 35), and $5 \mathrm{ml}$ of $20 \mathrm{mM} \mathrm{MnCl}$, were added to $39.5 \mathrm{ml}$ of the supernatant, and the mixture was incubated for $30 \mathrm{~min}$ at $30^{\circ} \mathrm{C}$.

Ubiquitination of BMI1. HEK293FT cells were transfected with either control siRNA or RASSF6targeted siRNA; $24 \mathrm{~h}$ later, the cells were further transfected with pCIneoFH-BMI1 and pCGN-HA-UBC. Forty-eight hours later, the cells were treated with $30 \mu \mathrm{M} \mathrm{MG}-132$ for $6 \mathrm{~h}$, harvested, and lysed in denaturing buffer $\mathrm{A}$ (6 $\mathrm{M}$ guanidinium hydrochloride, $100 \mathrm{mM} \mathrm{Na} \mathrm{HPO}_{4} / \mathrm{NaH}_{2} \mathrm{PO}_{4}, \mathrm{pH} 8.0,10 \mathrm{mM}$ Tris- $\mathrm{HCl}, \mathrm{pH} 8.0$, and $10 \mathrm{mM} \beta$-mercaptoethanol) by sonication. FH-BMI1 was isolated with $\mathrm{Ni}$ nitrilotriacetic acid (Ni-NTA)-agarose beads (Qiagen, Vento, Netherlands). The beads were washed with buffer $\mathrm{B}$ (8 $\mathrm{M}$ urea, $100 \mathrm{mM} \mathrm{Na} \mathrm{HPO}_{4} / \mathrm{NaH}_{2} \mathrm{PO}_{4}, \mathrm{pH} 8.0,10 \mathrm{mM}$ Tris- $\mathrm{HCl}, \mathrm{pH} 8.0$, and $10 \mathrm{mM}$ $\beta$-mercaptoethanol), and FLAG-His -tagged BM1 was eluted with buffer C (200 mM imidazole, $10 \mathrm{mM}$ Tris- $\mathrm{HCl}, \mathrm{pH} 6.7,0.72 \mathrm{M} \beta$-mercaptoethanol, 5\% [wt/vol] SDS, and 30\% glycerol). The eluents were analyzed by immunoblotting with anti-HA and anti-FLAG antibodies.

Statistical analysis. Statistical analyses were performed with Student's $t$ test for comparison between two samples and analysis of variance with Bonferroni's post hoc test for multiple comparisons using Prism software (GraphPad Software).

\section{SUPPLEMENTAL MATERIAL}

Supplemental material for this article may be found at https://doi.org/10.1128/MCB .00046-18.

SUPPLEMENTAL FILE 1, PDF file, 0.8 MB.

\section{ACKNOWLEDGMENTS}

We are grateful to Masa-Aki Ikeda (Tokyo Medical and Dental University), Akira Kikuchi (Osaka University), and Yue Xiong (University of North Carolina) for materials. Plasmid collections from the lentiviral human cDNA expression library (GE Dharmacon, UK) were supplied by the TMDU Gene Library.

S.H. and A.S. are supported by a MEXT scholarship. This work was supported by research grants from the Japan Society for the Promotion of Science (JSPS) (26460359 and 26293061) and the Mitsubishi Foundation (26138).

We declare that we have no conflict of interest.

\section{REFERENCES}

1. Avruch J, Zhou D, Fitamant J, Bardeesy N, Mou F, Barrufet LR. 2012. Protein kinases of the Hippo pathway: regulation and substrates. Semin Cell Dev Biol 23:770-784. https://doi.org/10.1016/j.semcdb.2012.07.002.

2. Volodko N, Gordon M, Salla M, Ghazaleh HA, Baksh S. 2014. RASSF tumor suppressor gene family: biological functions and regulation. FEBS Lett 588:2671-2684. https://doi.org/10.1016/j.febslet.2014.02.041.

3. Iwasa H, Hossain S, Hata Y. 2018. Tumor suppressor C-RASSF proteins.
Cell Mol Life Sci 75:1773-1787. https://doi.org/10.1007/s00018-018 $-2756-5$.

4. Hesson LB, Dunwell TL, Cooper WN, Catchpoole D, Brini AT, Chiaramonte R, Griffiths M, Chalmers AD, Maher ER, Latif F. 2009. The novel RASSF6 and RASSF10 candidate tumour suppressor genes are frequently epigenetically inactivated in childhood leukaemias. Mol Cancer 8:42. https:// doi.org/10.1186/1476-4598-8-42. 
5. Shinawi T, Hill V, Dagklis A, Baliakas P, Stamatopoulos K, Agathanggelou A, Stankovic T, Maher ER, Ghia P, Latif F. 2012. KIBRA gene methylation is associated with unfavorable biological prognostic parameters in chronic lymphocytic leukemia. Epigenetics 7:211-215. https://doi.org/10 4161/epi.7.3.19222.

6. Djos A, Martinsson T, Kogner P, Carén H. 2012. The RASSF gene family members RASSF5, RASSF6 and RASSF7 show frequent DNA methylation in neuroblastoma. Mol Cancer 11:40. https://doi.org/10.1186/1476-4598 $-11-40$.

7. Mezzanotte JJ, Hill V, Schmidt ML, Shinawi T, Tommasi S, Krex D, Schackert G, Pfeifer GP, Latif F, Clark GJ. 2014. RASSF6 exhibits promoter hypermethylation in metastatic melanoma and inhibits invasion in melanoma cells. Epigenetics 9:1496-1503. https://doi .org/10.4161/15592294.2014.983361.

8. Guo W, Dong Z, Guo Y, Shen S, Guo X, Kuang G, Yang Z. 2015. Decreased expression and frequent promoter hypermethylation of RASSF2 and RASSF6 correlate with malignant progression and poor prognosis of gastric cardia adenocarcinoma. Mol Carcinog 55:1655-1666. https://doi .org/10.1002/mc.22416.

9. Wen Y, Wang Q, Zhou C, Yan D, Qiu G, Yang C, Tang H, Peng Z. 2011. Decreased expression of RASSF6 is a novel independent prognostic marker of a worse outcome in gastric cancer patients after curative surgery. Ann Surg Oncol 18:3858-3867. https://doi.org/10.1245/s10434 -011-1668-5.

10. Ye HL, Li DD, Lin Q, Zhou Y, Zhou QB, Zeng B, Fu ZQ, Gao WC, Liu YM, Chen RW, Li ZH, Chen RF. 2015. Low RASSF6 expression in pancreatic ductal adenocarcinoma is associated with poor survival. World J Gastroenterol 21:6621-6630. https://doi.org/10.3748/wjg.v21.i21.6621.

11. Ikeda M, Hirabayashi S, Fujiwara N, Mori H, Kawata A, lida J, Bao Y, Sato Y, lida T, Sugimura H, Hata Y. 2007. Ras-association domain family protein 6 induces apoptosis via both caspase-dependent and caspaseindependent pathways. Exp Cell Res 313:1484-1495. https://doi.org/10 .1016/j.yexcr.2007.02.013.

12. Ikeda M, Kawata A, Nishikawa M, Tateishi Y, Yamaguchi M, Nakagawa K, Hirabayashi S, Bao Y, Hidaka S, Hirata Y, Hata Y. 2009. Hippo pathwaydependent and -independent roles of RASSF6. Sci Signal 2:ra59. https:// doi.org/10.1126/scisignal.2000300.

13. Withanage K, Nakagawa K, Ikeda M, Kurihara H, Kudo T, Yang Z, Sakane A, Sasaki T, Hata Y. 2012. Expression of RASSF6 in kidney and the implication of RASSF6 and the Hippo pathway in the sorbitol-induced apoptosis in renal proximal tubular epithelial cells. J Biochem 152: 111-119. https://doi.org/10.1093/jb/mvs056.

14. Iwasa H, Kudo T, Maimaiti S, Ikeda M, Maruyama J, Nakagawa K, Hata Y. 2013. The RASSF6 tumor suppressor protein regulates apoptosis and the cell cycle via MDM2 protein and p53 protein. J Biol Chem 288: 30320-30329. https://doi.org/10.1074/jbc.M113.507384.

15. Pan D. 2010. The Hippo signaling pathway in development and cancer. Dev Cell 19:491-505. https://doi.org/10.1016/j.devcel.2010.09.011.

16. Kodaka M, Hata Y. 2014. The mammalian Hippo pathway: regulation and function of YAP1 and TAZ. Cell Mol Life Sci 72:285-306. https://doi.org/ 10.1007/s00018-014-1742-9.

17. Meng Z, Moroishi T, Guan KL. 2016. Mechanisms of Hippo pathway regulation. Genes Dev 30:1-17. https://doi.org/10.1101/gad.274027.115.

18. Allen NP, Donninger H, Vos MD, Eckfeld K, Hesson L, Gordon L, Birrer MJ, Latif F, Clark GJ. 2007. RASSF6 is a novel member of the RASSF family of tumor suppressors. Oncogene 26:6203-6211. https://doi.org/10.1038/sj onc. 1210440.

19. Sarkar A, Iwasa H, Hossain S, Xu X, Sawada T, Shimizu T, Maruyama J, Arimoto-Matsuzaki K, Hata Y. 2017. Domain analysis of Ras-association domain family member 6 upon interaction with MDM2. FEBS Lett 591: 260-272. https://doi.org/10.1002/1873-3468.12551.

20. Weinberg RA. 1995. The retinoblastoma protein and cell cycle control. Cell 81:323-330. https://doi.org/10.1016/0092-8674(95)90385-2.

21. Vogelstein B, Lane D, Levine AJ. 2000. Surfing the p53 network. Nature 408:307-310. https://doi.org/10.1038/35042675.

22. Vousden KH, Lane DP. 2007. p53 in health and disease. Nat Rev Mol Cell Biol 8:275-283. https://doi.org/10.1038/nrm2147.

23. Dyson NJ. 2016. RB1: a prototype tumor suppressor and an enigma. Genes Dev 30:1492-1502. https://doi.org/10.1101/gad.282145.116.

24. Rubin SM. 2013. Deciphering the retinoblastoma protein phosphorylation code. Trends Biochem Sci 38:12-19. https://doi.org/10.1016/j.tibs .2012.10.007.

25. Macdonald JI, Dick FA. 2012. Posttranslational modifications of the retinoblastoma tumor suppressor protein as determinants of function. Genes Cancer 3:619-633. https://doi.org/10.1177/1947601912473305.

26. Dick FA, Rubin SM. 2013. Molecular mechanisms underlying RB protein function. Nat Rev Mol Cell Biol 14:297-306. https://doi.org/10.1038/ nrm3567.

27. Rubin SM, Gall AL, Zheng N, Pavletich NP. 2005. Structure of the Rb C-terminal domain bound to E2F1-DP1: a mechanism for phosphorylation-induced E2F release. Cell 123:1093-1106. https://doi .org/10.1016/j.cell.2005.09.044.

28. Burke JR, Deshong AJ, Pelton JG, Rubin SM. 2010. Phosphorylationinduced conformational changes in the retinoblastoma protein inhibit E2F transactivation domain binding. J Biol Chem 285:16286-16293. https://doi.org/10.1074/jbc.M110.108167.

29. Zarkowska T, Mittnacht S. 1997. Differential phosphorylation of the retinoblastoma protein by G1/S cyclin-dependent kinases. J Biol Chem 272:12738-12746. https://doi.org/10.1074/jbc.272.19.12738.

30. Lundberg AS, Weinberg RA. 1998. Functional inactivation of the retinoblastoma protein requires sequential modification by at least two distinct cyclin-cdk complexes. Mol Cell Biol 18:753-761. https://doi.org/10 .1128/MCB.18.2.753.

31. Ezhevsky SA, Nagahara H, Vocero-Akbani AM, Gius DR, Wei MC, Dowdy SF. 1997. Hypo-phosphorylation of the retinoblastoma protein ( $p R b)$ by cyclin D:Cdk4/6 complexes results in active pRb. Proc Natl Acad Sci U S A 94: 10699-10704. https://doi.org/10.1073/pnas.94.20.10699.

32. Antonucci LA, Egger JV, Krucher NA. 2014. Phosphorylation of the Retinoblastoma protein $(\mathrm{Rb})$ on serine-807 is required for association with Bax. Cell Cycle 13:3611-3617. https://doi.org/10.4161/15384101 .2014.964093.

33. Ren S, Rollins BJ. 2004. Cyclin C/cdk3 promotes Rb-dependent G0 exit. Cell 117:239-251. https://doi.org/10.1016/S0092-8674(04)00300-9.

34. Tschöp K, Conery AR, Litovchick L, Decaprio JA, Settleman J, Harlow E, Dyson N. 2011. A kinase shRNA screen links LATS2 and the pRB tumor suppressor. Genes Dev 25:814-830. https://doi.org/10.1101/ gad.2000211.

35. Kolupaeva V, Janssens V. 2013. PP1 and PP2A phosphatases-cooperating partners in modulating retinoblastoma protein activation. FEBS J 280: 627-643. https://doi.org/10.1111/j.1742-4658.2012.08511.x.

36. Ribeiro PS, Josué F, Wepf A, Wehr MC, Rinner O, Kelly G, Tapon N, Gstaiger M. 2010. Combined functional genomic and proteomic approaches identify a PP2A complex as a negative regulator of Hippo signaling. Mol Cell 39:521-534. https://doi.org/10.1016/j.molcel.2010.08.002.

37. Shi Z, Jiao S, Zhou Z. 2016. STRIPAK complexes in cell signaling and cancer. Oncogene 35:4549-4557. https://doi.org/10.1038/onc.2016.9.

38. Couzens AL, Knight JD, Kean MJ, Teo G, Weiss A, Dunham WH, Lin ZY, Bagshaw RD, Sicheri F, Pawson T, Wrana JL, Choi H, Gingras AC. 2013. Protein interaction network of the Mammalian hippo pathway reveals mechanisms of kinase-phosphatase interactions. Sci Signal 6:rs15. https://doi.org/10.1126/scisignal.2004712.

39. Barnoud T, Donninger H, Clark GJ. 2016. Ras regulates Rb via NORE1A. J Biol Chem 291:3114-3123. https://doi.org/10.1074/jbc.M115.697557.

40. Guo C, Zhang X, Pfeifer GP. 2011. The tumor suppressor RASSF1A prevents dephosphorylation of the mammalian STE20-like kinases MST1 and MST2. J Biol Chem 286:6253-6261. https://doi.org/10.1074/jbc .M110.178210.

41. Iwasa $H$, Jiang $X$, Hata Y. 2015. RASSF6; the putative tumor suppressor of the RASSF family. Cancers 7:2415-2426. https://doi.org/10.3390/ cancers7040899.

42. Uchida C, Miwa S, Kitagawa K, Hattori T, Isobe T, Otani S, Oda T, Sugimura H, Kamijo T, Ookawa K, Yasuda H, Kitagawa M. 2005. Enhanced Mdm2 activity inhibits pRB function via ubiquitin-dependent degradation. EMBO J 24:160-169. https://doi.org/10.1038/sj.emboj.7600486.

43. Jacobs JJ, Kieboom K, Marino S, DePinho RA, van Lohuizen M. 1999. The oncogene and Polycomb-group gene bmi-1 regulates cell proliferation and senescence through the ink4a locus. Nature 397:164-168. https:// doi.org/10.1038/16476.

44. Sahasrabuddhe AA, Dimri M, Bommi PV, Dimri GP. 2011. $\beta \operatorname{TrCP}$ regulates BMI1 protein turnover via ubiquitination and degradation. Cell Cycle 10:1322-1330. https://doi.org/10.4161/cc.10.8.15372.

45. Indovina P, Pentimalli F, Casini N, Vocca I, Giordano A. 2015. RB1 dual role in proliferation and apoptosis: cell fate control and implications for cancer therapy. Oncotarget 6:17873-17890. https://doi.org/10.18632/ oncotarget.4286.

46. Day ML, Foster RG, Day KC, Zhao X, Humphrey P, Swanson P, Postigo AA, Zhang SH, Dean DC. 1997. Cell anchorage regulates apoptosis through 
the retinoblastoma tumor suppressor/E2F pathway. J Biol Chem 272: 8125-8128. https://doi.org/10.1074/jbc.272.13.8125.

47. Ianari A, Natale T, Calo E, Ferretti E, Alesse E, Screpanti I, Haigis K, Gulino A, Lees JA. 2009. Proapoptotic function of the retinoblastoma tumor suppressor protein. Cancer Cell 15:184-194. https://doi.org/10.1016/j.ccr .2009.01.026.

48. Müller H, Bracken AP, Vernell R, Moroni MC, Christians F, Grassilli E, Prosperini E, Vigo E, Oliner JD, Helin K. 2001. E2Fs regulate the expression of genes involved in differentiation, development, proliferation, and apoptosis. Genes Dev 15:267-285. https://doi.org/10.1101/gad.864201.

49. Moroni MC, Hickman ES, Lazzerini Denchi E, Caprara G, Colli E, Cecconi F, Müller H, Helin K. 2001. Apaf-1 is a transcriptional target for E2F and p53. Nat Cell Biol 3:552-558. https://doi.org/10.1038/35078527.

50. Nahle Z, Polakoff J, Davuluri RV, McCurrach ME, Jacobson MD, Narita M, Zhang MQ, Lazebnik Y, Bar-Sagi D, Lowe SW. 2002. Direct coupling of the cell cycle and cell death machinery by E2F. Nat Cell Biol 4:859-864. https://doi.org/10.1038/ncb868.

51. Korah J, Falah N, Lacerte A, Lebrun JJ. 2012. A transcriptionally active pRb-E2F1-P/CAF signaling pathway is central to TGF $\beta$-mediated apoptosis. Cell Death Dis 3:e407. https://doi.org/10.1038/cddis.2012.146.

52. Pediconi N, lanari A, Costanzo A, Belloni L, Gallo R, Cimino L, Porcellini A, Screpanti I, Balsano C, Alesse E, Gulino A, Levrero M. 2003. Differential regulation of E2F1 apoptotic target genes in response to DNA damage. Nat Cell Biol 5:552-558. https://doi.org/10.1038/ncb998.
53. Banerjee Mustafi S, Chakraborty PK, Dwivedi SK, Ding K, Moxley KM, Mukherjee P, Bhattacharya R. 2017. BMI1, a new target of CK2 $\alpha$. Mol Cancer 16:56. https://doi.org/10.1186/s12943-017-0617-8.

54. Ma S, Tang J, Feng J, Xu Y, Yu X, Deng Q, Lu Y. 2008. Induction of p21 by $\mathrm{p} 65$ in p53 null cells treated with doxorubicin. Biochim Biophys Acta 1783:935-940. https://doi.org/10.1016/j.bbamcr.2008.01.008.

55. Vayssade M, Haddada H, Faridoni-Laurens L, Tourpin S, Valent A, Bénard J, Ahomadegbe JC. 2005. P73 functionally replaces p53 in adriamycintreated, p53-deficient breast cancer cells. Int J Cancer 116:860-869. https://doi.org/10.1002/ijc.21033.

56. Kawano S, Maruyama J, Nagashima S, Inami K, Qiu W, Iwasa H, Nakagawa K, Ishigami-Yuasa M, Kagechika H, Nishina H, Hata Y. 2015. A cell-based screening for TAZ activators identifies ethacridine, a widely used antiseptic and abortifacient, as a compound that promotes dephosphorylation of TAZ and inhibits adipogenesis in C3H10T1/2 cells. J Biochem 158:413-423. https://doi.org/10.1093/jb/mvv051.

57. Ohta T, Xiong Y. 2001. Phosphorylation- and Skp1-independent in vitro ubiquitination of E2F1 by multiple ROC-cullin ligases. Cancer Res 61: 1347-1353.

58. Bao $Y$, Nakagawa $K$, Yang Z, Ikeda M, Withanage $K$, Ishigami-Yuasa $M$, Okuno Y, Hata S, Nishina H, Hata Y. 2011. A cell-based assay to screen stimulators of the Hippo pathway reveals the inhibitory effect of dobutamine on the YAP-dependent gene transcription. J Biochem 150:199-208. https://doi.org/10.1093/jb/mvr063. 